\title{
Antimikrobielle Therapie bei Kindern und Jugendlichen mit Nieren- und Leberinsuffizienz
}

\author{
H. Kolve ${ }^{1,2}$ \\ G. Silling ${ }^{3}$ \\ J. Ritter ${ }^{1}$ \\ A. H. Groll ${ }^{1}$
}

\author{
Antimicrobial Agents in Pediatric Cancer Patients with Hepatic or Renal \\ Impairment
}

\section{Zusammenfassung}

In der Supportivtherapie von Kindern und Jugendlichen mit bösartigen Erkrankungen oder nach Blutstammzelltransplantation sind antimikrobielle Substanzen eine der am häufigsten eingesetzten Arzneimittel. Die meisten dieser Substanzen werden unverändert über die Nieren und/oder nach Metabolisierung über die Leber aus dem Körper eliminiert. Funktionsstörungen von Nieren und Leber haben z.T. ausgeprägte Effekte auf die Pharmakologie antimikrobieller Substanzen mit der Konsequenz einer Dosismodifikation, um unerwünschte Arzneimittelwirkungen vor allem durch Akkumulation der Muttersubstanz und/oder ihrer Metabolite zu verhindern. Voraussetzung zur Vermeidung derartig hervorgerufener Arzneimittelwirkungen ist die genaue Kenntnis häufig eingesetzter Substanzen und eine sorgfältige Abwägung von Nutzen und Risiken antimikrobieller Interventionen. Der vorliegende Beitrag enthält eine Übersicht über die Mechanismen der Clearance von Arzneimitteln bei normaler und eingeschränkter Nieren- und Leberfunktion, die Implikationen für die antimikrobielle Therapie und Dosierungsempfehlungen für pädiatrische Patienten mit bösartigen Erkrankungen und eingeschränkter Nieren- bzw. Leberfunktion.

\section{Schlüsselwörter}

Antimikrobielle Substanzen · Niereninsuffizienz • Leberinsuffizienz $\cdot$ Kinder $\cdot$ Krebs

\begin{abstract}
Antimicrobial agents are among the most frequently prescribed therapeutics in the supportive care of children and adolescents with cancer or following hematopoietic stem cell transplantation. Most of these agents are cleared from the body by elimination of unchanged drug by the kindney and/or metabolism by the liver. Impaired renal and hepatic function may have profound effects on the pharmacokinetics and pharmacodynamics of antimicrobial agents, necessitating modification of the dosage regimen in order to avoid toxicity through accumulation of the parent and/or its metabolites. Key to minimize such toxicities is a thorough understanding of the antimicrobial drug armamentarium and a careful evaluation of benefits and risks of antimicrobial interventions. This article reviews the mechanisms of renal and hepatic drug clearance in the normal state and in the state of functional impairment, their implications for antimicrobial therapy and dosage recommendations for pediatric cancer patients with impaired renal or hepatic function.
\end{abstract}

\section{Key words}

Antimicrobial agents · hepatic impairment • renal impairment · children · cancer

Institutsangaben

${ }^{1}$ Infektiologisches Forschungsprogramm, Klinik und Poliklinik für Kinderheilkunde,

Pädiatrische Hämatologie/Onkologie, Universitätsklinikum Münster

${ }^{2}$ Zentralapotheke, Universitätsklinikum Münster

${ }^{3}$ Medizinische Klinik und Poliklinik, Innere Medizin A, Universitätsklinikum Münster

Korrespondenzadresse

Priv.Doz. Dr. med. Andreas H. Groll · Klinik und Poliklinik für Kinder- und Jugendmedizin .

Pädiatrische Hämatologie/Onkologie · Universitätsklinikum Münster · Albert Schweitzer Straße 33 .

48129 Münster · Tel.: +49/251/8347742 · Fax: +49/251/83478 28 · E-mail: grollan@ukmuenster.de

Bibliografie

Klin Pädiatr 2005; 217 (Suppl 1): S150-S164 • @ Georg Thieme Verlag KG Stuttgart · New York

DOI 10.1055/s-2005-872509

ISSN 0300-8630 


\section{Einleitung}

In der Supportivtherapie von Kindern und Jugendlichen mit bösartigen Erkrankungen oder nach Blutstammzelltransplantation sind antimikrobielle Substanzen eine der am häufigsten eingesetzten Arzneimittel. Die meisten antimikrobiellen Substanzen werden unverändert über die Nieren und/oder nach Metabolisierung in der Leber aus dem Körper eliminiert. Funktionsstörungen von Nieren und Leber können ausgeprägte Effekte auf die Pharmakologie antimikrobieller Substanzen haben, die entweder nach einer therapeutischen Alternative oder nach einer Modifikation der Dosierung verlangen, um unerwünschte Arzneimittelwirkungen durch Akkumulation der Muttersubstanz und/oder ihrer Metabolite zu verhindern. Jüngere Untersuchungen zeigen jedoch, dass häufig keine der genannten Modifikationen vorgenommen werden mit der Konsequenz vermeidbarer Morbidität und hoher Folgekosten [22, 29].

Voraussetzung zur Vermeidung derartig hervorgerufener unerwünschter Arzneimittelwirkungen ist neben einer sorgfältigen Abwägung von Nutzen und Risiken antimikrobieller Interventionen die Integration spezieller pharmakologischer und dynamischer patienten-spezifischer Informationen. Diese Aufgabe obliegt in aller Regel dem verantwortlichen Arzt, der sie in der Regel unter Zeitdruck und ohne adäquate Ressourcen lösen muss. Die aktive Teilnahme eines klinischen Pharmakologen bzw. der Einsatz computerisierter Verordnungsprogramme [12] als Mittel der Qualitätssicherung der Arzneimitteltherapie stehen bedauerlicherweise bislang nur an wenigen Zentren zur Verfügung.

Der vorliegende Beitrag enthält eine Übersicht über die pharmakologischen Pinzipien der renalen und hepatischen Elimination von Arzneimitteln und deren Implikationen für die antimikrobielle Therapie sowie Dosierungsangaben für pädiatrische Patienten jenseits der Neugeborenenzeit mit eingeschränkter Leber- und Nierenfunktion. Die antimikrobielle Therapie bei Nierenersatzverfahren wird aufgrund ihrer Komplexität nicht im Detail behandelt.

\section{Antimikrobielle Therapie bei Niereninsuffizienz}

Die Nieren sind wesentlich verantwortlich für die Aufrechterhaltung der Homöostase des Wasser- und Elektrolythaushaltes. Änderungen der Nierenfunktion können erhebliche Auswirkungen auf die Pharmakologie antimikrobieller Substanzen haben. Die Kenntnis der hierbei beteiligten Vorgänge ist Voraussetzung für eine sichere und effektive Arzneimitteltherapie bei Patienten mit eingeschränkter Nierenfunktion.

\section{Mechanismen der renalen Exkretion von Arzneimitteln}

Arzneimittel können prinzipiell auf drei Wegen über die Nieren ausgeschieden werden [27]:

- durch glomeruläre Filtration werden Substanzen mit niedrigem Molekulargewicht eliminiert; limitierend ist die Plasmaeiweißbindung, d.h. nur der nicht gebundene Substanzanteil $\mathrm{f}_{\mathrm{U}}$ steht für die Filtration zur Verfügung:

Substanzspezifische Filtrationsrate $=\mathrm{GFR} \times \mathrm{f}_{\mathrm{U}} \times[$ Substanz $]$
- Im Gegensatz dazu ist die tubuläre Sekretion nicht durch die Plasmaeiweißbindung limitiert, d.h. freier und gebundener Substanzanteil stehen für die Sekretion zur Verfügung. Die tubuläre Sekretion kann kompetitiv und damit Ursache wichtiger Arzneimittelinteraktionen sein (Beispiel: Penizillin und Säuren).

- Die renale Elimination kann ferner durch tubuläre Reabsorption in Form passiver Diffusion oder aktiver Transportmechanismen beeinflusst werden.

Für die meisten Substanzen existieren keine detaillierten Untersuchungen zu den Mechanismen ihrer renalen Elimination; die renale Elimination („Clearance“) wird vereinfacht mit der Kreatininclearance korreliert. Obwohl diese vorwiegend die glomeruläre Filtrationsrate repräsentiert, erlaubt sie auch eine grobe Abschätzung der renalen Clearance von Substanzen, die einer ausgeprägten tubulären Sekretion oder Reabsorption unterliegen. Dies beruht auf einer intrinsischen Adaptation geschädigter Nephrone („glomerulär-tubuläre Balance“) mit dem Resultat einer Abnahme auch der glomerulären Filtrationsrate [4].

\section{Renale Clearance und Dosierung}

Unter Bedingungen des steady state bestimmen verabreichte Dosis und Clearance durch Elimination die Konzentrationen einer Substanz im Körper und damit ihre pharmakologischen Effekte. Der Begriff der „Clearance“ bezieht sich dabei auf das Verteilungsvolumen einer Substanz, das im steady state pro Zeiteinheit von dieser Substanz befreit wird [21].

Die Gesamtkörperclearance $\left(\mathrm{Cl}_{\mathrm{E}}\right)$ setzt sich für die meisten Substanzen aus einer renalen $\left(\mathrm{CL}_{\mathrm{R}}\right)$ und einer nichtrenalen $\left(\mathrm{CL}_{\mathrm{NR}}\right)$ Komponente zusammen:

$\mathrm{Cl}_{\mathrm{E}}=\mathrm{CL}_{\mathrm{R}}+\mathrm{CL}_{\mathrm{NR}}$

Die nichtrenale Komponente wird vereinfachend mit der hepatischen Clearance durch Metabolisierung gleichgesetzt. Diese kann mehrere parallele intrahepatische Vorgänge beinhalten, es können jedoch auch andere Organsysteme (Nieren, Darm, Lungen, Haut) metabolisch aktiv sein und zur Elimination beitragen. Eine Dosisanpassung bei Niereninsuffizienz ist anhand der o.g. Gleichung oder durch Konstruktion substanzspezifischer Nomogramme möglich, wenn Gesamtkörperclearance und prozentuale renale Ausscheidung der Substanz und die berechnete Kreatininclearance des Patienten vorliegen $[8,11]$.

Die Anpassung der Dosis bei Patienten mit eingeschränkter Nierenfunktion kann in der Praxis durch Reduktion der Einzeldosen und/oder durch Verlängerung des Dosisintervalles erfolgen. Berücksichtigt werden sollten dabei die pharmakodynamischen Parameter einer Substanz, die am besten mit der Wirksamkeit korrelieren [4].

Nach Schätzung der Gesamtkörperclearance kann die tägliche Dosis proportional zum Quotienten aus geschätzter Clearance und normaler Clearance bestimmt werden. Mittlere Substanzkonzentrationen werden so auf dem bei normaler Organfunktion vorliegenden Level gehalten, unabhängig davon, ob die Substanz als kontinuierliche Infusion oder als intermittierende Einzeldosen verabreicht wird. Dieser Ansatz ist z. B. für die antibakte- 
riellen Betalaktame intuitiv sinnvoll, die eine vorwiegend zeitabhängige bakterizide Aktivität und kurze postantibiotische Effekte besitzen.

Auf der anderen Seite ist es oft günstiger, Dosen von Substanzen mit relativ kurzer Halbwertszeit in Vielfachen der Eliminationshalbwertszeit zu verabreichen. Die erwartete Halbwertszeit $T_{1 / 2}$ kann aus dem Verteilungsvolumen $V_{d}$ und der Gesamtkörperclearance $\mathrm{CL}_{\mathrm{E}}$ durch die folgende Gleichung berechnet werden:

$\mathrm{T}_{1 / 2}=\left(0,693 \times \mathrm{V}_{\mathrm{d}}\right) / \mathrm{CL}_{\mathrm{E}}$

Die Dosis kann dann mit einem Dosierungsintervall verabreicht werden, das dem Vielfachen der verlängerten Halbwertszeit entspricht. Anpassungen des Dosisintervalles sind üblicherweise notwendig, wenn Verträglichkeit und Wirksamkeit Zielgrößen für Spitzen- und Talspiegel erfordern oder wenn die Auswahl von Einzeldosen limitiert ist. Ein Beispiel sind die Aminoglykoside, die eine konzentrationsabhängige bakterizide Aktivität und lange postantibiotische Effekte besitzen und deshalb bevorzugt durch Verlängerung des Dosierungsintervalles angepasst werden.

Die Zuverlässigkeit der hier beschriebenen, in der Praxis häufig eingesetzten Methoden hängt dabei von zwei Voraussetzungen ab, d.h. dass die nichtrenale Clearance einer Substanz bei Änderung der renalen Clearance konstant bleibt und dass die Gesamtkörperclearance linear zur Kreatininclearance abfällt [4].

\section{Pharmakologische Konsequenzen renaler Funktionsstörungen}

Eine verminderte Elimination von Substanzen mit relevanter renaler Clearance führt in erster Linie zu einer Akkumulation und damit potenziell toxischen Substanzkonzentrationen. Nierenfunktionsstörungen können jedoch auch Folgen für Metabolismus und Distribution haben:

- Nierenfunktionsstörungen können nicht nur die renale Elimination von Metaboliten vermindern, sondern direkt zu einer Verminderung oder Beschleunigung metabolischer Reaktionswege führen [28]. Ab welchem Grad der Nierenfunktionsstörung dies pharmakologisch relevant ist, ist dabei jedoch für die meisten Substanzen nicht bekannt.

- Nierenfunktionsstörungen können mit Veränderungen der Plasmaeiweißbindung von Arzneimitteln einhergehen. So ist die Plasmaeiweißbindung nahezu aller saurer Substanzen bei urämischen Patienten vermindert [26]; dies wird auf eine verminderte Albuminkonzentration, strukturelle Veränderungen der Bindungsstellen bzw. eine Verdrängung von Arzneimittel von den Bindungsstellen des Albumins durch bei Urämie akkumulierende organische Moleküle zurückgeführt. Eine Abnahme der Proteinbindung führt zu einer Vergrößerung des Verteilungsvolumens und einer beschleunigten intrinsischen hepatischen Clearance restriktiv eliminierter Substanzen.

- Einige Substanzen können bei Nierenfunktionsstörungen auch ein niedrigeres Verteilungsvolumen haben, was im Falle des Digoxins mit einer Abnahme von Gewebskonzentrationen einer spezifischen $\mathrm{Na} / \mathrm{K}$-ATPase erklärt wurde, in anderen Fällen vom Mechanismus her ungeklärt ist [4].

- Neben Faktoren wie Übelkeit, Erbrechen, Gastroparese, der Gabe von Bikarbonat, Antazida, oder Phosphatbindern kön- nen Nierenfunktionsstörungen mit einer intrinsisch verminderten Absorption peroral verabreichter Substanzen assoziiert sein: So kann die Absorption von D-Xylose, einem funktionellen Marker der absorptiven Funktionen des Dünndarms, bei Patienten mit chronischem Nierenversagen verlangsamt und quantitativ reduziert sein [10].

\section{Antimikrobielle Therapie bei renaler Funktionsstörung}

Die Abschätzung der Nierenfunktion auf alleiniger Basis des Serumkreatinins ist gefährlich. Die Höhe des Serumkreatinins ist durch den Quotienten aus seiner Syntheserate und seiner Eliminationsrate bestimmt. Eine geringe Muskelmasse und zunehmendes Lebensalter gehen mit einer verminderten endogenen Kreatininsynthese einher; trotz Vorliegens einer relevanten Nierenfunktionsstörung können hier Kreatininkonzentrationen im Serum im Normbereich liegen und eine ungestörte Funktion vortäuschen.

Zuverlässiger, wenn auch weitaus nicht optimal ist die Bestimmung der Kreatininclearance. Der Begriff der „Clearance“ wurde zuerst Ende der 20er-Jahre des vorigen Jahrhunderts in die klinische Pharmakologie eingeführt und bezieht sich auf das Blutvolumen, das pro Zeiteinheit von einer Substanz befreit wird [21] Die Bestimmung der Kreatininclearance ist über die Jahre zu einer klinischen Routinemethode zur Abschätzung der Nierenfunktion geworden; sie wird wie folgt berechnet:

$\mathrm{CL}_{\mathrm{CR}}=(\mathrm{U} \times \mathrm{V}) / \mathrm{P}$

wobei U die Kreatininkonzentration in einer über eine bestimmte Zeitperiode gesammelten Urinmenge $V$ und $P$ die Kreatininkonzentration im Serum ist.

Im klinischen Alltag ist die Sammlung der zur direkten Bestimmung der Kreatininclearance benötigten Urinproben oft unpraktisch und auch unzuverlässig, da häufig Einzelportionen verworfen bzw. nicht gesammelt werden [20,36]. Bei erwachsenen Patienten kann die Kreatininclearance entweder nach Standardnomogrammen oder nach der Formel von Cockroft und Gault [8] (Tab. 1) abgeschätzt werden.

Die Formel von Cockcroft und Gault kann nicht zur Abschätzung der Kreatininclearance bei pädiatrischen Patienten verwendet werden, da die relative Muskelmasse bei Kindern nicht der von Erwachsenen entspricht. Auf Basis dieser Tatsache wurde von Schwartz et al. [33] eine alternative, in der derzeitigen klinischen Praxis weitgehend akzeptierte Gleichung zur Abschätzung der Kreatininclearance bei pädiatrischen Patienten entwickelt (Tab.1).

Da beiden Formeln Durchschnittspersonen zugrunde liegen, werden sie bei extremen Werten („outlayer“) von Körpergewicht und Serumkreatinin, bei Patienten mit niedriger endogener Kreatininproduktion, Anasarka und rasch wechselnder Nierenfunktion zunehmend ungenau. In diesen Situationen kann eine akkurate Bestimmung der Kreatininclearance nur durch eine exakte Messung der Kreatininexkretionsrate im Urin (Sammelurin) erfolgen [4]. Eine exakte, wenn auch in der klinischen Praxis sehr aufwendige Alternative ist die Berechnung der glomerulären Filtrationsleistung mit Hilfe niedrigmolekularer exogener Marker wie Inulin, das nicht hepatisch metabolisert und durch 
Tab. 1 Verfahren zur Abschätzung der Kreatininclearance*

Formel von Cockcroft und Gault:

Männer:

$\mathrm{Cl}_{\mathrm{CR}}[\mathrm{ml} / \mathrm{min}]=(140-$ Lebensalter $) \times($ Gewicht $[\mathrm{kg}]) / 72$

$\times$ Serumkreatinin $[\mathrm{mg} / \mathrm{dl}]$

Frauen:

$\mathrm{Cl}_{\mathrm{CR}}[\mathrm{ml} / \mathrm{min}]=((140-$ Lebensalter $) \times($ Gewicht $[\mathrm{kg}]) / 72$

$\times$ Serumkreatinin $[\mathrm{mg} / \mathrm{dl}]) \times 0,85$

Formel von Schwartz et al.:

$\mathrm{CL}_{\mathrm{CR}}\left[\mathrm{ml} / \mathrm{min} / 1,73 \mathrm{~m}^{2}\right]=\mathrm{k} \times$ Körpergröße $[\mathrm{cm}] /$ Serumkreatinin $[\mathrm{mg} / \mathrm{dl}]$

Neugeborene und Kinder $<1$ Jahr: $k=0,45$

Kinder von 1-13 Jahren: $\quad k=0,55$

Mädchen von 13-20 Jahren: $\quad k=0,57$

Jungen von 13-20 Jahren: $\quad k=0,70$

* Bei extremen individuellen Werten von Körpergewicht und Serumkreatinin, bei Patienten mit niedriger endogener Kreatininproduktion, Anasarka und rasch wechselnder Nierenfunktion sind beide Verfahren zunehmend ungenau. In diesen Situationen kann eine akkurate Bestimmung der Kreatininclearance nur durch eine exakte Messung der Kreatininexkretionsrate im Urin (Sammelurin) erfolgen [4].

glomeruläre Filtration ohne tubuläre Sekretion oder Reabsorption rasch und vollständig eliminiert wird $[13,25]$.

Bei der Anpassung der Dosierung renal eliminierter antimikrobieller Substanzen bei eingeschränkter Nierenfunktion sind folgende Grundsätze zu beachten [20]:

- Die erste Dosis („loading dose“, Aufsättigung) ist in aller Regel unabhängig von der Nierenfunktion. Eine Dosisanpassung erfolgt erst bei den nachfolgenden Dosen („maintenance dose“, Erhaltungsdosis).

- Die kalkulierte, angepasste Dosis stellt lediglich eine Schätzung der adäquaten Dosis dar. Individuelle Unterschiede der Disposition können durch Messungen von Blut- bzw. Plasmakonzentrationen erfasst werden. Diese sind in der klinischen Praxis jedoch nur bei potenziell toxischen Substanzen mit geringer therapeutischer Breite indiziert.

- Ein Auf- bzw. Abrunden der berechneten Clearance zu der nächsten Dezimalen ist unbedenklich.

- Die berechnete Erhaltungsdosis ist nicht statisch. Die Nierenfunktion muss unter Therapie kontinuierlich beurteilt und die Dosis gegebenenfalls erneut modifiziert werden.

Relevante pharmakokinetische Parameter, Eliminationswege, intrinsische Nephrotoxizität und empfohlene Dosismodifikationen bei Niereninsuffizienz von häufig in der pädiatrischen Onkologie eingesetzten antimikrobiellen Substanzen sind in Tab. 2 aufgelistet. Es lassen sich folgende zusammenfassende, allgemeine Aussagen treffen:

- Bei Substanzen, die vorwiegend unverändert und nahezu ausschließlich renal eliminiert werden, eine geringe therapeutische Breite besitzen und potenziell toxische Konzentrationen erreichen können, ist eine Dosisanpassung bereits bei leichter bzw mittelgradiger Niereninsuffizienz erforderlich. Hierzu gehören

- alle Aminoglykoside

- 5-Flucytosin

- Aciclovir, Famciclovir, Valaciclovir, Ganciclovir, Valganciclovir, Foscarnet
- Vancomycin und Teicoplanin

- Streptomycin

sowie, mit größerer therapeutischer Breite, Fosfomycin und Fluconazol.

Eine Dosisanpassung kann auch bei Substanzen, die unverändert oder in metabolisierter Form in relevantem Ausmaß renal eliminiert werden vor allem bei höhergradiger Niereninsuffizienz erforderlich sein. Diese Gruppe umfasst

- Penicillin G/V

- Ampicillin, Amoxicillin; Oxacillin, Flucloxacillin; Mezlocillin, Piperacillin

- Ampicillin/Sulbactam, Amoxicillin/Clavulansäure, Piperacillin/Tazobactam

- Cefazolin, Cefuroxim, Cefotaxim, Ceftriaxon, Ceftazidim, Cefepim

- Cefalexin, Cefaclor, Cefuroximaxetil, Loracarbef, Cefpodoximproxetil, Cefipim, Ceftibuten

- Aztreonam; Imipenem und Meropenem

- Clindamycin

- das Oxazolidinon Linezolid

- Metronidazol

- Ciprofloxacin, Levofloxacin, Moxifloxacin

- sulfonamidhaltige Kombinationen wie Trimethoprim/Sulfamethoxazol und Sulfadiazin/Pyrimethamin

- die intravenösen Cyclodextrin-Zubereitungen von Itraconazol und Voriconazol

- das antimykotische Allylamin Terbinafin

- die Virustatika Brivudin und Oseltamivir

- die Tuberkulostatika Isoniazid und Ethambutol

Eine Dosisanpassung von Substanzen, die unverändert oder in metabolisierter Form nicht oder nur in geringem Ausmaß renal eliminiert werden, ist bei leichter bzw. mittelschwerer Niereninsuffizienz der Regel nicht erforderlich. Zu dieser Gruppe gehören:

- Doxycyclin

- Erythromycin, Roxithromycin, Azithromycin, Clarithromycin

- das Ketolid Telithromycin

- das Streptogramin Quinupristin/Dalfopristin

- Chloramphenicol

- Rifampicin

- Amphotericin B; liposomales Amphotericin B

- orale Zubereitungen von Itraconazol und Voriconazol

- das Echinocandin Caspofungin

\section{Intrinsische Nephrotoxizität antimikrobieller Substanzen}

Während die Nieren nur einen Bruchteil der Körpermasse ausmachen, erhalten sie 20-25\% des Herzminutenvolumens der Ruhephase. Ihr Kapillarbett ist dadurch großen Mengen an Arzneistoff ausgesetzt. Daneben übertreffen die Konzentrationen glomerulär filtrierter bzw. tubulär sezernierter Substanzen im Primär- und Sekundärharn die Konzentrationen in der systemischen Zirkulation in der Regel um ein Vielfaches.

Mit Ausnahme von konventionellem Amphotericin B, dessen Nephrotoxizität überwiegend vaskulär verstanden wird, finden sich Antiinfektiva mit hohem Potenzial einer intrinsischen Nierenschädigung vor allem in der Gruppe vorwiegend unverändert renal eliminierter Substanzen und umfassen u.a. die Aminoglykoside, 
Tab. 2 Pharmakokinetische Eckdaten, intrinsische Toxizität und empfohlene Dosisanpassung bei Patienten mit Leber- und Niereninsuffizienz

\begin{tabular}{|c|c|c|c|c|c|c|c|c|c|c|}
\hline \multirow[t]{2}{*}{ Wirkstoff } & \multirow[t]{2}{*}{$\begin{array}{l}\text { Protein- } \\
\text { bindung (\%) }\end{array}$} & $\begin{array}{l}\text { Verteilungs- } \\
\text { volumen }(I / k g)\end{array}$ & $\begin{array}{l}\text { hepatischer } \\
\text { Metabolismus }\end{array}$ & \multirow{2}{*}{$\begin{array}{l}\text { renale } \\
\text { Elimination (\%) } \\
T S=\text { tub. Sekretion } \\
G F=\text { glom. Filtrat. } \\
U=\text { unverändert } \\
I=\text { inaktive Met. } \\
A=\text { aktive Met. }\end{array}$} & \multirow{2}{*}{$\begin{array}{l}\text { intrinsische } \\
\text { Hepatotoxizität } \\
\text { TA, Transaminasen }\end{array}$} & \multirow[t]{2}{*}{$\begin{array}{l}\text { intrinsische } \\
\text { Nephrotoxizität }\end{array}$} & \multirow{2}{*}{$\begin{array}{l}\text { Dosisanpassung } \\
\text { bei Leber- } \\
\text { insuffizienz }\end{array}$} & \multirow{2}{*}{$\begin{array}{l}\text { Dosisanpassung bei } \\
\text { Niereninsuffizienz } \\
\text { Kreatininclearance } \\
\text { in ml/min; } \\
\text { \% Normaldosis bzw. } \\
\text { Dosisintervall (DI) }\end{array}$} & \multirow{2}{*}{$\begin{array}{l}\text { Dialyse } \\
\text { HD, Hämo- } \\
\text { dialyse } \\
\text { P, Perito- } \\
\text { neal- } \\
\text { dialyse }\end{array}$} & \multirow[t]{2}{*}{$\begin{array}{l}\text { pädiatr. } \\
\text { Zulassung }\end{array}$} \\
\hline & & $\begin{array}{ll}+ & <0,5 \\
++ & 0,5-1,5 \\
+++ & >1,5-5 \\
++++ & >5\end{array}$ & $\begin{array}{ll}+ & \text { gering } \\
++ & \text { hoch } \\
+++ & \text { CYP } 450\end{array}$ & & & & & & & \\
\hline \multicolumn{11}{|l|}{ Penizilline } \\
\hline Penicillin G/V & $45-65$ & $\begin{array}{l}\text { + bei EW } \\
\text { ++ bei KD }\end{array}$ & ++ & $\begin{array}{l}\text { TS: 90/GF: } 10 \\
\text { A: 50-70, I: } 20\end{array}$ & $\begin{array}{l}\text { AM-Hepatitis, } \\
\text { Cholestase }\end{array}$ & Nephritis, interst. & keine & $\begin{array}{l}\text { 30-15: DI } 8 \text { h } \\
<15: \text { DI } 12 \mathrm{~h}\end{array}$ & $\begin{array}{l}H D: j \\
P: n\end{array}$ & FG \\
\hline Ampicillin & $17-20$ & + & + & $\begin{array}{l}\text { oral: U: } 40 \\
\text { i.v.: U: } 73\end{array}$ & $\mathrm{TA} \uparrow$ & $\begin{array}{l}\text { Kristallurie bei } \\
\text { hohen Dosen }\end{array}$ & keine & $\begin{array}{l}30-20: 66 \% \\
<20: 33 \%\end{array}$ & $\begin{array}{l}H D: j \\
P: n\end{array}$ & KD \\
\hline Amoxicillin & $17-20$ & + & + & U: 50-75 & $\mathrm{TA} \uparrow$ & Nephritis, interst. & keine & $\begin{array}{l}30-20: 66 \% \\
<20: 33 \%\end{array}$ & $\begin{array}{l}H D: j \\
P: n\end{array}$ & KD \\
\hline Oxacillin & $92-95$ & + & ++ & $\begin{array}{l}\mathrm{U}: 40 \\
(\mathrm{GF}+\mathrm{TS})\end{array}$ & $\begin{array}{l}\text { TA } \uparrow \text {, Cholestase, } \\
\text { AM-Hepatitis }\end{array}$ & - & ja, ohne Angaben & $<10: \max .4 \times 1 \mathrm{~g}$ & $\begin{array}{l}H D: j \\
P: n\end{array}$ & FG \\
\hline Mezlocillin & $30-40$ & + & ++ & A: $55-70$ & $\mathrm{TA} \uparrow$ & - & $\begin{array}{l}\text { evtl. bei gleichz. } \\
\text { Niereninsuffi- } \\
\text { zienz }\end{array}$ & $<10:$ DI 12 h & $\begin{array}{l}H D: j \\
P: n\end{array}$ & FG \\
\hline Piperacillin & $16-21$ & + & + & $\begin{array}{l}\text { U: 60-80 } \\
\text { (GF > TS) }\end{array}$ & $\begin{array}{l}\text { TA } \uparrow \\
\text { Bili } \uparrow \text { u./o. AP } \uparrow\end{array}$ & $\begin{array}{l}\text { Kreatinin } \uparrow \\
\text { Nephritis, interst. }\end{array}$ & $\begin{array}{l}\text { evtl. bei gleichz. } \\
\text { Niereninsuffi- } \\
\text { zienz }\end{array}$ & $\begin{array}{l}\text { 40-20: DI } 8 \mathrm{~h} \\
<20: \text { DI } 12 \mathrm{~h}\end{array}$ & $\begin{array}{l}H D: j \\
P: n\end{array}$ & FG \\
\hline $\begin{array}{l}\text { Ampicillin (A)/ } \\
\text { Sulbactam (S) }\end{array}$ & & + & + & $\begin{array}{l}\text { (A) U: } 80 \% \\
\text { (S) U: } 80 \% \text { (TS) }\end{array}$ & $\begin{array}{l}\text { TA } \uparrow \\
\text { Bili } \uparrow\end{array}$ & Nephritis, interst. & keine & $\begin{array}{l}\text { 30-15: DI } 12 \mathrm{~h} \\
\text { 14-5: DI } 24 \mathrm{~h}\end{array}$ & $\begin{array}{l}H D: j \\
P: n\end{array}$ & KD \\
\hline $\begin{array}{l}\text { Amoxicillin (A)/ } \\
\text { Clavulansäure (C) }\end{array}$ & $\begin{array}{l}\text { (A): } 17-22 \\
\text { (C): } 22\end{array}$ & $\begin{array}{l}\text { (A): + } \\
\text { (C): + }\end{array}$ & $\begin{array}{l}\text { (A): }+ \\
\text { (C): }++\end{array}$ & $\begin{array}{l}\text { (A): } \cup: 50-75 \\
\text { (C): U: } 20-40\end{array}$ & $\begin{array}{l}\text { TA } \uparrow, \text { Cholestase, } \\
\text { AM-Hepatitis }\end{array}$ & $\begin{array}{l}\text { Kristallurie bei } \\
\text { hohen Dosen }\end{array}$ & $\begin{array}{l}\text { KI bei schwerer } \\
\text { Leberinsuffizienz }\end{array}$ & $\begin{array}{l}30-10: 50 \% \\
<10: \text { DI } 24 \mathrm{~h}\end{array}$ & $\begin{array}{l}H D: j \\
P: n\end{array}$ & $\geq 2$ Jahre \\
\hline $\begin{array}{l}\text { Piperacillin }(P) / \\
\text { Tazobactam (T) }\end{array}$ & $\begin{array}{l}(P): 30 \\
(T): 30\end{array}$ & + & + & $\begin{array}{l}\text { (P): U: } 50-80 \\
(\mathrm{~T}): \mathrm{U}+\mathrm{I}: 80\end{array}$ & $\begin{array}{l}\text { TA } \uparrow \\
\text { Bili } \uparrow, A P \uparrow\end{array}$ & $\begin{array}{l}\text { Kreatinin } \uparrow, \\
\text { Nephritis, interst. }\end{array}$ & keine & $\begin{array}{l}\geq 12 \mathrm{~J}:<20: \text { DI } 12 \mathrm{~h} \\
<12 \mathrm{~J}:<50: 70 \% 8 \mathrm{~h}\end{array}$ & $\begin{array}{l}H D: j \\
P: n\end{array}$ & $\geq 2$ Jahre \\
\hline \multicolumn{11}{|l|}{ Cephalosporine } \\
\hline Cefazolin & $65-92$ & + & + & $\begin{array}{l}\text { U: } 56-100 \\
\text { (GF >>TS) }\end{array}$ & $\begin{array}{l}\text { TA } \uparrow, \text { Cholestase, } \\
\text { AM-Hepatitis }\end{array}$ & Nephritis, interst. & keine & $\begin{array}{l}70-40: 60 \% \text { DI } 12 \mathrm{~h} \\
40-20: 25 \% \text { DI } 12 \mathrm{~h} \\
<20: 10 \% \text { DI } 24 \mathrm{~h}\end{array}$ & $H D: j$ & $\geq 1$ Monat \\
\hline Cefuroxim-Natrium & 33 & +-++ & + & $\begin{array}{l}\mathrm{U}: \geq 90 \\
(\mathrm{GF}, \mathrm{TS})\end{array}$ & $\mathrm{TA} \uparrow, \mathrm{AP} \uparrow$ & $\begin{array}{l}\text { Kreatinin } \uparrow \\
\text { Nephritis, interst. }\end{array}$ & keine & $\begin{array}{l}\text { 30-10: DI } 12 \mathrm{~h} \\
\text { <10: DI } 24 \mathrm{~h}\end{array}$ & $\begin{array}{l}H D: j \\
P: n\end{array}$ & $\geq 1$ Monat \\
\hline Cefotaxim & $25-40$ & + & + & $\begin{array}{l}\text { U: } 50-60 \\
\text { A: } 20\end{array}$ & TA $\uparrow$, Bili $\uparrow, A P \uparrow$ & $\begin{array}{l}\text { Kreatinin } \uparrow \\
\text { Nephritis, interst. }\end{array}$ & keine & 10-6: 50\% & $\begin{array}{l}H D: j \\
P: n\end{array}$ & FG \\
\hline Ceftriaxon & $83-96$ & + & + & U: 33-67 (GF) & $\mathrm{TA} \uparrow, \mathrm{AP} \uparrow$ & $\begin{array}{l}\text { Kreatinin } \uparrow \\
\text { Oligurie }\end{array}$ & $\begin{array}{l}\text { nur bei gleichz. } \\
\text { Niereninsuffi- } \\
\text { zienz }\end{array}$ & $<10$ : max. 2 g TD & $\begin{array}{l}H D: j \\
P: j\end{array}$ & NG \\
\hline Ceftazidim & 10 & + & + & U: 90-96 (GF) & TA $\uparrow$, Cholestase & Kreatinin $\uparrow$ & keine & $\begin{array}{l}\text { 30-16: DI } 24 \mathrm{~h} \\
\text { 15-6: 50\% DI } 24 \mathrm{~h}\end{array}$ & $\begin{array}{l}H D: j \\
P: j\end{array}$ & NG \\
\hline Cefepim & $<19$ & + & + & U: 85 (GF) & TA $\uparrow, A P \uparrow, B i l i \uparrow$ & Kreatinin $\uparrow$ & keine & $\begin{array}{l}<30: 50-100 \% \text { DI } 24 \mathrm{~h} \\
<10: 25-50 \% \text { DI } 24 \mathrm{~h}\end{array}$ & $\begin{array}{l}H D: j \\
P: n\end{array}$ & $\geq 1$ Monat \\
\hline
\end{tabular}


Tab. 2 Fortsetzung

\begin{tabular}{|c|c|c|c|c|c|c|c|c|c|c|}
\hline Wirkstoff & $\begin{array}{l}\text { Protein- } \\
\text { bindung (\%) }\end{array}$ & $\begin{array}{l}\text { Verteilungs- } \\
\text { volumen }(1 / \mathrm{kg}) \\
+\quad<0,5 \\
+++\quad 0,5-1,5 \\
+++\quad>1,5-5 \\
+++>5\end{array}$ & $\begin{array}{l}\text { hepatischer } \\
\text { Metabolismus } \\
+\quad \text { gering } \\
++ \text { hoch } \\
+++ \text { CYP } 450\end{array}$ & $\begin{array}{l}\text { renale } \\
\text { Elimination (\%) } \\
T S=\text { tub. Sekretion } \\
G F=\text { glom. Filtrat. } \\
U=\text { unverändert } \\
I=\text { inaktive Met. } \\
A=\text { aktive Met. }\end{array}$ & $\begin{array}{l}\text { intrinsische } \\
\text { Hepatotoxizität } \\
\text { TA, Transaminasen }\end{array}$ & $\begin{array}{l}\text { intrinsische } \\
\text { Nephrotoxizität }\end{array}$ & $\begin{array}{l}\text { Dosisanpassung } \\
\text { bei Leber- } \\
\text { insuffizienz }\end{array}$ & $\begin{array}{l}\text { Dosisanpassung bei } \\
\text { Niereninsuffizienz } \\
\text { Kreatininclearance } \\
\text { in ml/min; } \\
\text { \% Normaldosis bzw. } \\
\text { Dosisintervall (DI) }\end{array}$ & $\begin{array}{l}\text { Dialyse } \\
\text { HD, Hämo- } \\
\text { dialyse } \\
\text { P, Perito- } \\
\text { neal- } \\
\text { dialyse }\end{array}$ & $\begin{array}{l}\text { pädiatr. } \\
\text { Zulassung }\end{array}$ \\
\hline Cefalexin & $6-15$ & + & + & $\begin{array}{l}\text { U: 69-100 } \\
\text { (GF, TS) }\end{array}$ & $\begin{array}{l}\text { TA } \uparrow \text {, Cholestase, } \\
\text { AM-Hepatitis }\end{array}$ & Nephritis, interst. & keine & $\begin{array}{l}\text { 30-15: DI 8-12 h } \\
\text { 15-5: DI 24 h }\end{array}$ & HD: j & SG \\
\hline Cefachlor & 25 & + & + & $\begin{array}{l}\text { U+A: } 50-80 \\
\text { (GF, TS) }\end{array}$ & $\mathrm{TA} \uparrow, \mathrm{AP} \uparrow$ & Nephritis, interst. & keine & keine & $\begin{array}{l}H D: j \\
P: j\end{array}$ & KD \\
\hline Cefuroxim-Axetil & $33-50$ & + & + & $\begin{array}{l}\text { U: 50-90 } \\
\text { (GF u. TS) }\end{array}$ & $\mathrm{TA} \uparrow$ & - & keine & max. $1 \mathrm{~g}$ Tagesdosis & $H D: j$ & $\geq 3$ Monate \\
\hline Loracarbef & 25 & + & + & $59-66$ & $\begin{array}{l}\text { TA } \uparrow \text {, Cholestase, } \\
\text { AM-Hepatitis }\end{array}$ & $\begin{array}{l}\text { Kreatinin } \uparrow \\
\text { Nephritis, interst. }\end{array}$ & keine & 49-10: $50 \%$ & HD: j & $\geq 6$ Monate \\
\hline Cefpodoximproxetil & 40 & + & + & U: 80 & $\begin{array}{l}\text { TA } \uparrow \text {, Cholestase, } \\
\text { AM-Hepatitis }\end{array}$ & Kreatinin $\uparrow$ & keine & $\begin{array}{l}\text { 40-10: DI } 24 \text { h } \\
<10: \text { DI } 48 \text { h }\end{array}$ & $\begin{array}{l}H D: j \\
P: n\end{array}$ & SG \\
\hline Cefixim & 65 & ++ & + & U: 50-55 & $\begin{array}{l}\mathrm{TA} \uparrow, \mathrm{AP} \uparrow, \\
\text { Cholestase }\end{array}$ & Kreatinin $\uparrow$ & keine & $<20: \mathrm{Kdr} .4 \mathrm{mg} / \mathrm{kg} / \mathrm{d}$ & HD: $n$ & $\geq 3$ Monate \\
\hline Ceftibuten & $62-64$ & + & + & $\begin{array}{l}\text { U: } 60-70 \\
\text { Trans-Isomer: }<15\end{array}$ & TA $\uparrow$, Bili $\uparrow$ & Nephropathie, tox. & keine & $29-5: 50 \%$ & $H D: j$ & $\geq 3$ Monate \\
\hline \multicolumn{11}{|l|}{ andere $\beta$-Laktame } \\
\hline Aztreonam & 56 & + & + & $\begin{array}{l}\text { U: 60-70 } \\
\text { (GF, TS) }\end{array}$ & $\begin{array}{l}\text { TA } \uparrow, \text { AP } \uparrow, \\
\text { Cholestase }\end{array}$ & Kreatinin $\uparrow$ & $\begin{array}{l}\text { Monitoring } \\
\text { UAWs }\end{array}$ & $\begin{array}{l}30-10: 50 \% \\
<10: 25 \%\end{array}$ & HD: j & $\geq 1$ Woche \\
\hline $\begin{array}{l}\text { Imipenem (IP)/ } \\
\text { Cilastin (C) }\end{array}$ & $\begin{array}{l}\text { (IP): } 20 \\
\text { (C): } 40\end{array}$ & + & + & $\begin{array}{l}\text { (IP): U: 70, I: } 30 \\
\text { (C): U: } 80, A: 10\end{array}$ & $\begin{array}{l}\mathrm{TA} \uparrow, \mathrm{AP} \uparrow, \text { Bili } \uparrow, \\
\text { AM-Hepatitis }\end{array}$ & $\begin{array}{l}\text { Kreatinin } \uparrow, \\
\text { Polyurie, Oligurie, } \\
\text { Anurie }\end{array}$ & keine & $\begin{array}{l}70-41: 75 \% \\
40-21: 50 \% \\
20-6: 50 \% \text { DI } 12 \mathrm{~h}\end{array}$ & $H D: j$ & $\geq 3$ Monate \\
\hline Meropenem & 2 & $(+)$ & + & U: 70 & TA $\uparrow$, Bili $\uparrow, A P \uparrow$ & Kreatinin $\uparrow$ & $\begin{array}{l}\text { Monitoring } \\
\text { UAWs }\end{array}$ & $\begin{array}{l}\text { 50-26: DI } 12 \mathrm{~h} \\
\text { 25-10: } 50 \% \text { DI } 12 \mathrm{~h} \\
<10: 50 \% \text { DI } 24 \mathrm{~h}\end{array}$ & $\begin{array}{l}H D: j \\
P: n\end{array}$ & $\geq 3$ Monate \\
\hline \multicolumn{11}{|l|}{ Chinolone } \\
\hline Ciprofloxacin & $20-30$ & +++ & +++ & $\begin{array}{l}\text { p.o.: U: } 30, A, I: 22 \\
\text { i.v.: U: } 57, A, I: 24\end{array}$ & $\begin{array}{l}\text { TA } \uparrow, \text { Bili } \uparrow, \text { AP } \uparrow, \\
\text { AM-Hepatitis }\end{array}$ & $\begin{array}{l}\text { Nephritis, interst., } \\
\text { Nierenversagen }\end{array}$ & keine & $<30: 50 \%$ & $\begin{array}{l}H D: j \\
P: j\end{array}$ & $K D \geq 5 \mathrm{~J}$. \\
\hline Levofloxacin & $30-40$ & +++ & +++ & U: 85 & $\begin{array}{l}\text { TA } \uparrow, \text { Bili } \uparrow, \\
\text { AM-Hepatitis }\end{array}$ & $\begin{array}{l}\text { Kreatinin } \uparrow, \\
\text { Nephritis, interst. }\end{array}$ & keine & $\begin{array}{l}50-20: 50 \% \\
19-10: 25 \% \\
<10: 25 \% \text {, doppelt. DI }\end{array}$ & $\begin{array}{l}H D: j \\
P: j\end{array}$ & $\begin{array}{l}\text { KI bei KD } \\
\text { u. JGD im } \\
\text { Wachstum }\end{array}$ \\
\hline Moxifloxacin & $40-42$ & +++ & + & $\mathrm{U}: 40$ & TA $\uparrow$, Bili $\uparrow$ & Kreatinin $\uparrow$ & $\begin{array}{l}\text { KI bei Child } \\
\text { Pugh C oder } \\
\text { TA }>\times 5 \text { ONW }\end{array}$ & keine & $\begin{array}{l}H D: n \\
P: j\end{array}$ & $\begin{array}{l}\text { KI bei KD } \\
\text { u. JGD im } \\
\text { Wachstum }\end{array}$ \\
\hline
\end{tabular}


Tab. 2 Fortsetzung

\begin{tabular}{|c|c|c|c|c|c|c|c|c|c|c|}
\hline Wirkstoff & $\begin{array}{l}\text { Protein- } \\
\text { bindung (\%) }\end{array}$ & 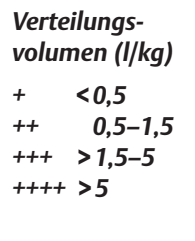 & $\begin{array}{l}\text { hepatischer } \\
\text { Metabolismus } \\
+\quad \text { gering } \\
++ \text { hoch } \\
+++ \text { CYP } 450\end{array}$ & $\begin{array}{l}\text { renale } \\
\text { Elimination (\%) } \\
\text { TS = tub. Sekretion } \\
G F=\text { glom. Filtrat. } \\
U=\text { unverändert } \\
I=\text { inaktive Met. } \\
A=\text { aktive Met. }\end{array}$ & $\begin{array}{l}\text { intrinsische } \\
\text { Hepatotoxizität } \\
\text { TA, Transaminasen }\end{array}$ & $\begin{array}{l}\text { intrinsische } \\
\text { Nephrotoxizität }\end{array}$ & $\begin{array}{l}\text { Dosisanpassung } \\
\text { bei Leber- } \\
\text { insuffizienz }\end{array}$ & $\begin{array}{l}\text { Dosisanpassung bei } \\
\text { Niereninsuffizienz } \\
\text { Kreatininclearance } \\
\text { in ml/min; } \\
\text { \% Normaldosis bzw. } \\
\text { Dosisintervall (DI) }\end{array}$ & $\begin{array}{l}\text { Dialyse } \\
\text { HD, Hämo- } \\
\text { dialyse } \\
\text { P, Perito- } \\
\text { neal- } \\
\text { dialyse }\end{array}$ & $\begin{array}{l}\text { pädiatr. } \\
\text { Zulassung }\end{array}$ \\
\hline \multicolumn{11}{|c|}{ Makrolide/Ketolide } \\
\hline Erythromycin & $60-70$ & ++ & +++ & $\begin{array}{l}\text { p. o.: U: }<10, A: 2,5 \\
\text { i. v.: U: }<10, A:<15\end{array}$ & $\begin{array}{l}\text { TA } \uparrow, \text { Cholestase, } \\
\text { AM-Hepatitis }\end{array}$ & Nephritis, interst. & $\begin{array}{l}\text { strenge Indika- } \\
\text { tion, Monitoring } \\
\text { UAWs }\end{array}$ & Anurie: $\max .2 \mathrm{~g} / \mathrm{d}$ & $\begin{array}{l}\text { HD: } n \\
P: n\end{array}$ & SG \\
\hline Clarithromycin & 72 & +++ & +++ & U: $20-30$ & $\mathrm{TA} \uparrow, \mathrm{AP} \uparrow$ & - & $\begin{array}{l}\text { leichte-mäßige: } \\
\text { Monitoring } \\
\text { UAWs } \\
\text { schwere LI: KI }\end{array}$ & $<30: 50 \%$ & $\begin{array}{l}\text { HD: } n \\
P: n\end{array}$ & FG \\
\hline Roxithromycin & 95 & + & +++ & $\mathrm{U}: 10$ & $\begin{array}{l}\text { TA } \uparrow, A P \uparrow, \text { Bili } \uparrow, \\
\text { AM-Hepatits }\end{array}$ & - & $\begin{array}{l}\text { leichte-mäßige: } \\
\text { Monitoring } \\
\text { UAWs } \\
\text { schwere LI: } 50 \%\end{array}$ & keine & & $\mathrm{KD}$ \\
\hline Azithromycin & 12 & ++++ & ++ & $\mathrm{U}:<12$ & $\begin{array}{l}\text { TA } \uparrow, \text { Cholestase, } \\
\text { AM-Hepatitis }\end{array}$ & $\begin{array}{l}\text { Nephritis, interst., } \\
\text { Nierenversagen }\end{array}$ & Child-Pugh C: KI & keine & $\begin{array}{l}\text { HD: } n \\
P: n\end{array}$ & KD \\
\hline Telithromycin & $60-70$ & +++ & +++ & U: 12-14 & $\begin{array}{l}\text { TA } \uparrow, \text { Cholestase, } \\
\text { AM-Hepatitis }\end{array}$ & - & $\begin{array}{l}\text { keine, nur bei } \\
\text { gleichz. Nieren- } \\
\text { funktionsstörung }\end{array}$ & $<30: 50 \%$ & $H D: j$ & $\geq 12$ Jahre \\
\hline \multicolumn{11}{|c|}{ andere antibakterielle Substanzen } \\
\hline Doxycyclin & $80-90$ & ++ & +++ & $20-60$ & $\begin{array}{l}\text { Überdosierung: } \\
\text { Leberschädigung, } \\
\text { Pankreatitis }\end{array}$ & $\begin{array}{l}\text { Kreatinin } \uparrow, \\
\text { Nephritis, interst., } \\
\text { Nierenversagen }\end{array}$ & keine & $\begin{array}{l}\text { keine; cave i.v. Lsg. } \\
\text { (Akkum. d. Carriers) }\end{array}$ & $\begin{array}{l}\text { HD: } n \\
P: n\end{array}$ & $\geq 8$ Jahre \\
\hline Linezolid & 31 & $(+)$ & ++ & $\begin{array}{l}\text { U: } 50 \\
\text { I: } 40\end{array}$ & $\mathrm{TA} \uparrow, \mathrm{AP} \uparrow, \mathrm{Bili} \uparrow$ & Kreatinin $\uparrow$ & $\begin{array}{l}\text { Monitoring } \\
\text { UAWs }\end{array}$ & $\begin{array}{l}<30 \text { : strenge Indika- } \\
\text { tion (akkum. Metabo- } \\
\text { lite) }\end{array}$ & $H D: j$ & $\geq 18$ Jahre \\
\hline Clindamycin & $60-94$ & ++ & ++ & U/Metabolite: 33 & TA $\uparrow$, Bili $\uparrow$ & - & $\begin{array}{l}\text { mittelschwer: } \\
\text { DI } 8 \mathrm{~h}\end{array}$ & keine & $\begin{array}{l}\text { HD: } n \\
P: n\end{array}$ & $\geq 1$ Monat \\
\hline Teicoplanin & 90 & ++ & + & U: 70 (GF) & $\mathrm{TA} \uparrow, \mathrm{AP} \uparrow$ & $\begin{array}{l}\text { Kreatinin } \uparrow, \\
\text { Nierenversagen }\end{array}$ & keine & $\begin{array}{l}\text { 60-40: } 50 \% \\
<40: \text { Dosis }=\mathrm{Cl}^{*} \times \mathrm{D} / \mathrm{Cl} \\
\text { (akt. Kreaclearance } \\
\times \text { Standarddosis/nor- } \\
\text { male Kreaclearance) }\end{array}$ & $\begin{array}{l}\text { HD: } n \\
P: n\end{array}$ & NG \\
\hline Metronidazol & $<20$ & +-++ & +++ & $\begin{array}{l}\text { U: } 10 \\
\text { Metabolite: } 60-70\end{array}$ & TA $\uparrow$, Pankreatitis & - & schwere LI: KI & keine & $\begin{array}{l}H D: j \\
P: n\end{array}$ & $\mathrm{KD}$ \\
\hline Vancomycin & 55 & +-++ & + & U: 75-90 (GF) & - & $\begin{array}{l}\text { Kreatinin } \uparrow, \\
\text { Nephritis, interst., } \\
\text { Nierenversagen }\end{array}$ & keine & $\begin{array}{l}<90 \text { : initial } 15 \mathrm{mg} / \mathrm{kg} \text {, } \\
\text { danach < } 90: 90 \% \text {, } \\
<80: 80 \% \text { usf. } \\
\text { therapeut. Monitoring }\end{array}$ & & SG \\
\hline
\end{tabular}


Tab. 2 Fortsetzung

\begin{tabular}{|c|c|c|c|c|c|c|c|c|c|c|}
\hline Wirkstoff & $\begin{array}{l}\text { Protein- } \\
\text { bindung (\%) }\end{array}$ & $\begin{array}{l}\text { Verteilungs- } \\
\text { volumen }(1 / \mathrm{kg}) \\
+\quad<0,5 \\
+\quad \quad 0,5-1,5 \\
++\quad>1,5-5 \\
+++ \\
+++>5\end{array}$ & $\begin{array}{l}\text { hepatischer } \\
\text { Metabolismus } \\
+\quad \text { gering } \\
++ \text { hoch } \\
+++ \text { CYP } 450\end{array}$ & $\begin{array}{l}\text { renale } \\
\text { Elimination (\%) } \\
T S=\text { tub. Sekretion } \\
G F=\text { glom. Filtrat. } \\
U=\text { unverändert } \\
I=\text { inaktive Met. } \\
A=\text { aktive Met. }\end{array}$ & $\begin{array}{l}\text { intrinsische } \\
\text { Hepatotoxizität } \\
\text { TA, Transaminasen }\end{array}$ & $\begin{array}{l}\text { intrinsische } \\
\text { Nephrotoxizität }\end{array}$ & $\begin{array}{l}\text { Dosisanpassung } \\
\text { bei Leber- } \\
\text { insuffizienz }\end{array}$ & $\begin{array}{l}\text { Dosisanpassung bei } \\
\text { Niereninsuffizienz } \\
\text { Kreatininclearance } \\
\text { in ml/min; } \\
\text { \% Normaldosis bzw. } \\
\text { Dosisintervall (DI) }\end{array}$ & $\begin{array}{l}\text { Dialyse } \\
\text { HD, Hämo- } \\
\text { dialyse } \\
\text { P, Perito- } \\
\text { neal- } \\
\text { dialyse }\end{array}$ & $\begin{array}{l}\text { pädiatr. } \\
\text { Zulassung }\end{array}$ \\
\hline Fosfomycin & $<3$ & +++ & + & U: 90 (GF) & $\mathrm{TA} \uparrow, \mathrm{AP} \uparrow(<1 \%)$ & - & keine & $\begin{array}{l}45-19: 60 \% \text { DI } 8 \text { h } \\
18-9: 33-40 \% \text { DI } 12 \text { h } \\
8-2: 16-20 \% \text { DI } 24 \mathrm{~h}\end{array}$ & $\begin{array}{l}H D: j \\
P: j\end{array}$ & FG \\
\hline $\begin{array}{l}\text { Quinupristin }(Q) / \\
\text { Dalfopristin }(P)\end{array}$ & $55-78$ & $\begin{array}{l}\text { (Q): ++ } \\
\text { (D): }++\end{array}$ & $\begin{array}{l}++ \\
\text { CYP3A4- } \\
\text { Inhibit. } \\
\text { kein Substrat }\end{array}$ & $\begin{array}{l}\text { (Q): U + Met.: } 15 \\
\text { (D): U + Met.: } 19\end{array}$ & $\begin{array}{l}\text { Kreatinin } \uparrow, \text { Bili } \uparrow \text {, } \\
\text { TA } \uparrow, \text { AM-Hepatitis }\end{array}$ & Kreatinin $\uparrow$ & $\begin{array}{l}\text { Child-Pugh B: } \\
75 \% \\
\text { Child-Pugh C: KI } \\
\text { Bili >3×ONW: KI }\end{array}$ & keine & HD: $n$ & $\geq 18$ Jahre \\
\hline $\begin{array}{l}\text { Sulfamethoxazol (S)/ } \\
\text { Trimethoprim (T) }\end{array}$ & $\begin{array}{l}\text { (S): } 65 \\
(\mathrm{~T}): 40\end{array}$ & $\begin{array}{l}(\mathrm{S}):+ \\
(\mathrm{T}):+++\end{array}$ & $\begin{array}{l}(\mathrm{S}):+++ \\
(\mathrm{T}):+\end{array}$ & $\begin{array}{l}\text { (S): U: } 15-20 \\
\text { (T): U: } 50-75\end{array}$ & $\begin{array}{l}\text { TA } \uparrow, \text { Cholestase, } \\
\text { Leberzellnekrosen }\end{array}$ & $\begin{array}{l}\text { Kreatinin } \uparrow, \\
\text { Nephritis, interst. }\end{array}$ & $\begin{array}{l}\text { schwerer Leber- } \\
\text { schaden: KI }\end{array}$ & $\begin{array}{l}30-15: 50 \% \\
<15: \mathrm{KI}\end{array}$ & $\begin{array}{l}H D: j \\
P: j\end{array}$ & $\geq 2$ Monate \\
\hline Sulfadiazin & 55 & + & ++ & Metabolite: 57 & Cholestase & Nephritis, interst. & $\begin{array}{l}\text { leichte-mäßige: } \\
\text { rel. KI; } \\
\text { schwere: KI }\end{array}$ & $\begin{array}{l}\text { leichte Nieren- } \\
\text { funktionsstörung: } \\
\text { relative KI; <25: KI }\end{array}$ & $\begin{array}{l}H D: j \\
P: j\end{array}$ & $\geq 2$ Monate \\
\hline Chloramphenicol & $40-53$ & ++ & ++ & 90, davon U: 5-12 & TA $\uparrow$, Ikterus & - & schwere: KI & keine & $\begin{array}{l}H D: j \\
P: n\end{array}$ & FG \\
\hline Amikacin & $4-10$ & + & + & U: $60-82$ & $\mathrm{TA} \uparrow, \mathrm{AP} \uparrow$ & $\begin{array}{l}\text { Kreatinin } \uparrow, \\
\text { Tubulotoxizität }\end{array}$ & keine & $\begin{array}{l}\text { initial: } 7,5 \mathrm{mg} / \mathrm{kg} \mathrm{KG} \text {, } \\
\text { dann alle } 12 \mathrm{~h} \\
\text { Dosis }=\mathrm{Cl} \times \mathrm{D} / \mathrm{Cl} \\
\text { (akt. Kreaclearance } \\
\times \text { Standarddosis/nor- } \\
\text { male Kreaclearance) } \\
\text { therapeut. Monitoring }\end{array}$ & $\begin{array}{l}H D: j \\
P: j\end{array}$ & KD \\
\hline $\begin{array}{l}\text { Gentamicin, } \\
\text { Tobramycin }\end{array}$ & $<10$ & + & + & $\mathrm{U:}>90$ (GF) & $\mathrm{TA} \uparrow, \mathrm{AP} \uparrow, \mathrm{Bili} \uparrow$ & $\begin{array}{l}\text { Krea } \uparrow, \text { Nieren- } \\
\text { funktionsstörung }\end{array}$ & keine & $\begin{array}{l}<100 \text { : initial } 1 \mathrm{mg} / \mathrm{kg} \text {, } \\
\text { dann Erhaltung, } \\
\mathrm{DI} 8 \mathrm{~h} \text {, } \\
\text { Dosis }=\mathrm{Cl}^{*} \times \mathrm{D} / \mathrm{Cl} \\
\text { (akt. Kreaclearance } \\
\times \text { Standarddosis/nor- } \\
\text { male Kreaclearance) } \\
\text { therapeut. Monitoring }\end{array}$ & HD: j & $\geq 1$ Monat \\
\hline \multicolumn{11}{|l|}{ Tuberkulostatika } \\
\hline Ethambutol & $8,3-39$ & +++ & + & U: 50-90 & - & - & keine & therap. Monitoring & HD: j & $\geq 10$ Jahre \\
\hline Isoniazid & 30 & ++ & +++ & $5-30$ & TA $\uparrow$, Bili $\uparrow$ & Mikrohämaturie & spiegelgesteuert & $\begin{array}{l}\text { keine, evtl. } 1-2 \text { thera- } \\
\text { piefreie Tage }\end{array}$ & $\begin{array}{l}H D: j \\
P: j\end{array}$ & KD \\
\hline Pyrimethamin & 87 & +++ & ++ & $\begin{array}{l}\text { U: }<4 \\
\text { Met.: } 23\end{array}$ & $\mathrm{TA} \uparrow, \mathrm{AP} \uparrow$ & Hämaturie & $\begin{array}{l}\text { Dosisanpassung } \\
\text { erwägen }\end{array}$ & $\begin{array}{l}\text { Dosisanpassung } \\
\text { erwägen }\end{array}$ & & SG \\
\hline Pyrazinamid & $5-10$ & ++ & +++ & $\begin{array}{l}\text { U: }<15 \\
\text { Met : } 70\end{array}$ & Leberschäden & $\mathrm{HN} \uparrow$ & schwere: KI & <20: DI 2 × wöchentl. & HD: j & $\geq 10$ Jahre \\
\hline
\end{tabular}


Tab. 2 Fortsetzung

\begin{tabular}{|c|c|c|c|c|c|c|c|c|c|c|}
\hline Wirkstoff & $\begin{array}{l}\text { Protein- } \\
\text { bindung (\%) }\end{array}$ & 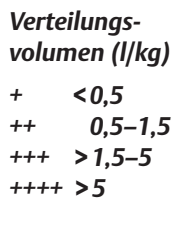 & $\begin{array}{l}\text { hepatischer } \\
\text { Metabolismus } \\
+\quad \text { gering } \\
++ \text { hoch } \\
+++ \text { CYP } 450\end{array}$ & $\begin{array}{l}\text { renale } \\
\text { Elimination (\%) } \\
T S=\text { tub. Sekretion } \\
G F=\text { glom. Filtrat. } \\
U=\text { unverändert } \\
I=\text { inaktive Met. } \\
A=\text { aktive Met. }\end{array}$ & $\begin{array}{l}\text { intrinsische } \\
\text { Hepatotoxizität } \\
\text { TA, Transaminasen }\end{array}$ & $\begin{array}{l}\text { intrinsische } \\
\text { Nephrotoxizität }\end{array}$ & $\begin{array}{l}\text { Dosisanpassung } \\
\text { bei Leber- } \\
\text { insuffizienz }\end{array}$ & $\begin{array}{l}\text { Dosisanpassung bei } \\
\text { Niereninsuffizienz } \\
\text { Kreatininclearance } \\
\text { in ml/min; } \\
\text { \% Normaldosis bzw. } \\
\text { Dosisintervall (DI) }\end{array}$ & $\begin{array}{l}\text { Dialyse } \\
\text { HD, Hämo- } \\
\text { dialyse } \\
\text { P, Perito- } \\
\text { neal- } \\
\text { dialyse }\end{array}$ & $\begin{array}{l}\text { pädiatr. } \\
\text { Zulassung }\end{array}$ \\
\hline Rifampicin & $70-90$ & ++ & +++ & $\mathrm{U}, \mathrm{A}: 15-30$ & $\mathrm{TA} \uparrow, \mathrm{AP} \uparrow, \mathrm{Bili} \uparrow$ & Nierenversagen & schwere: KI & keine & $\begin{array}{l}\text { HD: } n \\
P: n\end{array}$ & $\geq 2$ Monate \\
\hline Streptomycin & $34-35$ & + & + & U: 50-60 & $\mathrm{TA} \uparrow, \mathrm{AP} \uparrow$ & Tubulusschaden & keine & $\begin{array}{l}\text { 60-50: } 54 \% \\
\text { 50-40: } 45 \% \\
40-30: 36 \%\end{array}$ & $H D: j$ & $\geq 12$ Jahren \\
\hline \multicolumn{11}{|l|}{ Antimykotika } \\
\hline $\begin{array}{l}\text { Amphotericin } B \\
\text { Deoxycholat }\end{array}$ & 90 & ++++ & + & 40 & $\begin{array}{l}\text { TA } \uparrow, \text { AP } \uparrow, \text { Bili } \uparrow, \\
\text { Leberfunktionsst. }\end{array}$ & $\begin{array}{l}\text { Kreatinin } \uparrow \text {, } \\
\text { Oligurie, Anurie, } \\
\text { Hypomagnesemie, } \\
\text { Hypokaliämie }\end{array}$ & $\begin{array}{l}\text { schwer: alternati- } \\
\text { ve Substanzen }\end{array}$ & $\begin{array}{l}\text { 75-50: alternative } \\
\text { Substanzen }\end{array}$ & $\begin{array}{l}\text { HD: } n \\
P: n\end{array}$ & KD \\
\hline $\begin{array}{l}\text { liposomales } \\
\text { Amphotericin B }\end{array}$ & $\mathrm{n} / \mathrm{a}$ & + & + & $>10$ & $\begin{array}{l}\text { TA } \uparrow, A P \uparrow, \text { Bili } \uparrow, \\
\text { Leberfunktionsst. }\end{array}$ & $\begin{array}{l}\text { Kreatinin } \uparrow \text {, } \\
\text { Hypomagnesemie, } \\
\text { Hypokaliämie }\end{array}$ & keine & keine & & KD \\
\hline Flucytosin & 5 & ++ & + & U: 65-90 & $\begin{array}{l}\text { TA } \uparrow \text {, sehr selten: } \\
\text { Leberzellschaden }\end{array}$ & keine & $\begin{array}{l}\text { keine; Monito- } \\
\text { ring hepatischer } \\
\text { UAWs }\end{array}$ & $\begin{array}{l}\text { 40-20: DI } 12 \text { h; } \\
\text { 20-10: DI } 24 \text { h; } \\
\text { <10: DI nach Plasma- } \\
\text { konzentration }\end{array}$ & $\begin{array}{l}H D: j \\
P: j\end{array}$ & FG \\
\hline Fluconazol & 12 & ++ & +++ & U: 80 & $\begin{array}{l}\text { TA } \uparrow, \text { AP } \uparrow, \text { Bili } \uparrow, \\
\text { AM-Hepatitis, sel- } \\
\text { ten Leberversagen }\end{array}$ & Kreatinin $\uparrow$ (selten) & $\begin{array}{l}\text { keine; Monito- } \\
\text { ring hepatischer } \\
\text { UAWs }\end{array}$ & $\begin{array}{l}\text { 50-11: } \operatorname{Tag} 1+2: \\
100 \% \text {, danach } \\
50 \% \text { DI } 24 \mathrm{~h}\end{array}$ & $\begin{array}{l}H D: j \\
P: j\end{array}$ & $\geq 1 \mathrm{Jahr}$ \\
\hline Itraconazol & 99 & ++++ & +++ & $U+I<1$ & $\begin{array}{l}\text { TA } \uparrow, \text { Ikterus, AM- } \\
\text { Hepatitis, schwere } \\
\text { Hepatotox. }\end{array}$ & Kreatinin $\uparrow$ (selten) & $\begin{array}{l}\text { keine; Monito- } \\
\text { ring hepatischer } \\
\text { UAWs }\end{array}$ & $\begin{array}{l}<30: \text { KI für i.v. } \\
\text { Zubereitung } \\
\text { (Cyclodextrin!) } \\
\text { p.o.: } \downarrow \text { Bioverfüg- } \\
\text { barkeit, therapeut. } \\
\text { Monitoring }\end{array}$ & HD: N & $\geq 18$ Jahre \\
\hline Voriconazol & 58 & +++ & +++ & $\begin{array}{l}\text { U: }<2 \\
\text { Met.: } 80\end{array}$ & $\begin{array}{l}\text { TA } \uparrow, \text { Bili } \uparrow \text {, Leber- } \\
\text { versagen }\end{array}$ & $\begin{array}{l}\text { Nierenversagen, } \\
\text { Nephritis, Tubulus- } \\
\text { nekrose (selten) }\end{array}$ & $\begin{array}{l}\text { Child-Pugh A+B: } \\
\text { initial } 100 \% \text {, } \\
\text { danach } 50 \% \\
\text { Child-P. C: KI }\end{array}$ & $\begin{array}{l}<50 \text { : für i.v. } \\
\text { Zubereitung } \\
\text { (Cyclodextrin!) }\end{array}$ & & $\geq 2$ Jahre \\
\hline Terbinafin & 99 & ++++ & +++ & I: 70 & $\begin{array}{l}\text { Cholestase, Ikterus, } \\
\text { Leberversagen }\end{array}$ & - & $\begin{array}{l}\text { chron./akute } \\
\text { Lebererkran- } \\
\text { kungen: KI }\end{array}$ & $<50: 50 \%$ & & $\geq 18$ Jahre \\
\hline Caspofungin & 97 & $\mathrm{n} / \mathrm{a}$ & + & $\begin{array}{l}\text { U: }<5 \\
\text { Met: } 41\end{array}$ & $\mathrm{TA} \uparrow, \mathrm{AP} \uparrow, \mathrm{Bili} \uparrow$ & - & $\begin{array}{l}\text { Child-Pugh 7-9: } \\
35 \text { mg/d; Child- } \\
\text { Pugh >9: KI }\end{array}$ & keine & HD: $n$ & $\geq 18$ Jahre \\
\hline
\end{tabular}


Tab. 2 Fortsetzung

\begin{tabular}{|c|c|c|c|c|c|c|c|c|c|c|}
\hline Wirkstoff & $\begin{array}{l}\text { Protein- } \\
\text { bindung (\%) }\end{array}$ & $\begin{array}{l}\text { Verteilungs- } \\
\text { volumen }(1 / \mathrm{kg}) \\
+\quad<0,5 \\
++\quad 0,5-1,5 \\
+++\quad>1,5-5 \\
+++>5\end{array}$ & $\begin{array}{l}\text { hepatischer } \\
\text { Metabolismus } \\
+\quad \text { gering } \\
++ \text { hoch } \\
+++ \text { CYP } 450\end{array}$ & $\begin{array}{l}\text { renale } \\
\text { Elimination (\%) } \\
\text { TS = tub. Sekretion } \\
\text { GF = glom. Filtrat. } \\
\begin{array}{l}U=\text { unverändert } \\
I=\text { inaktive Met. } \\
A=\text { aktive Met. }\end{array}\end{array}$ & $\begin{array}{l}\text { intrinsische } \\
\text { Hepatotoxizität } \\
\text { TA, Transaminasen }\end{array}$ & $\begin{array}{l}\text { intrinsische } \\
\text { Nephrotoxizität }\end{array}$ & $\begin{array}{l}\text { Dosisanpassung } \\
\text { bei Leber- } \\
\text { insuffizienz }\end{array}$ & $\begin{array}{l}\text { Dosisanpassung bei } \\
\text { Niereninsuffizienz } \\
\text { Kreatininclearance } \\
\text { in ml/min; } \\
\text { \% Normaldosis bzw. } \\
\text { Dosisintervall (DI) }\end{array}$ & $\begin{array}{l}\text { Dialyse } \\
\text { HD, Hämo- } \\
\text { dialyse } \\
\text { P, Perito- } \\
\text { neal- } \\
\text { dialyse }\end{array}$ & $\begin{array}{l}\text { pädiatr. } \\
\text { Zulassung }\end{array}$ \\
\hline \multicolumn{11}{|l|}{ Virustatika } \\
\hline Aciclovir & $9-33$ & ++ & + & $\begin{array}{l}\text { U: } 62-91 \\
\text { I: } 10-15\end{array}$ & $\begin{array}{l}\text { TA } \uparrow, \text { Bili } \uparrow, \\
\text { AM-Hepatitis }\end{array}$ & Kreatinin $\uparrow$ & keine & $\begin{array}{l}\text { 50-25: } 100 \% \text { DI } 12 \mathrm{~h} \\
25-10: 100 \% \text { DI } 24 \mathrm{~h} \\
<10: 50 \% \text { DI } 24 \mathrm{~h}\end{array}$ & $\begin{array}{l}H D: j \\
P: j\end{array}$ & NG \\
\hline Valaciclovir & $9-33$ & ++ & ++ & $\begin{array}{l}\text { A: (Aciclovir) } \\
\text { 62-91; I: 10-15 }\end{array}$ & $\begin{array}{l}\text { TA } \uparrow, \text { Bili } \uparrow, \\
\text { AM-Hepatitis }\end{array}$ & Kreatinin $\uparrow$ & keine & $\begin{array}{l}\text { 30-15: DI } 12 \text { h } \\
<15: \text { DI } 24 \text { h }\end{array}$ & $\begin{array}{l}H D: j \\
P: j\end{array}$ & $\geq 18$ Jahre \\
\hline Ganciclovir & $1-2$ & ++ & + & $\mathrm{U}: 90(\mathrm{GF}+\mathrm{TS})$ & $\mathrm{TA} \uparrow, \mathrm{AP} \uparrow$ & Kreatinin $\uparrow$ & keine & $\begin{array}{l}\text { Initialtherapie: } \\
\text { 69-50: } 50 \% \\
\text { 49-25: 50\% DI } 24 \mathrm{~h} \\
\text { 24-10: } 25 \% \text { DI } 24 \mathrm{~h} \\
\text { Erhaltungstherapie: } \\
\text { 69-50: } 50 \% \\
\text { 49-25: } 25 \% \\
\text { 24-10: } 12,5 \%\end{array}$ & $H D: j$ & KD \\
\hline Valganciclovir & $1-2$ & ++ & + & $\begin{array}{l}\text { A (Ganciclovir): } 90 \\
\text { (GF + TS) }\end{array}$ & $\mathrm{TA} \uparrow, \mathrm{AP} \uparrow$ & Kreatinin $\uparrow$ & keine & $\begin{array}{l}\text { Initialtherapie: } \\
\text { 39-25: } 50 \% \text { DI } 24 \text { h } \\
\text { 24-10: } 50 \% \text { DI } 48 \text { h } \\
\text { Erhaltungstherapie: } \\
\text { 39-25: 50\% DI } 48 \text { h } \\
\text { 24-10: } 50 \% \\
\text { 2×/Woche }\end{array}$ & $H D: j$ & $\geq 18$ Jahre \\
\hline Famciclovir & $<20$ & ++ & ++ & Metabolite: 73 & Ikterus & & keine & 39-10: $50 \%$ & $H D: j$ & $\geq 18$ Jahre \\
\hline Cidofovir & $<10$ & & + & U: $80-100$ & & $\begin{array}{l}\text { Kreatinin } \uparrow, \text { Nieren- } \\
\text { vers., Proteinurie }\end{array}$ & $\begin{array}{l}\text { keine } \\
\text { Erfahrungen }\end{array}$ & $\begin{array}{l}<55 \text { oder Proteinurie } \\
>100 \text { mg/dl: Kl }\end{array}$ & & $\geq 18$ Jahre \\
\hline Brivudin & $>95$ & ++ & ++ & $\begin{array}{l}\text { Metabolite: } 65 \\
\text { U: }<1\end{array}$ & $\begin{array}{l}\text { TA } \uparrow, A P \uparrow, \\
\text { Fettleber }\end{array}$ & Harnstoff $\uparrow$ & keine & keine & & $>18$ Jahre \\
\hline Foscarnet & $<20$ & +-++ & + & U: 73-94 (GF + TS) & $\mathrm{TA} \uparrow$ & $\begin{array}{l}\text { Kreatinin } \uparrow, \\
\text { Nierenversagen }\end{array}$ & keine & $\begin{array}{l}\text { Komplex in Abhängig- } \\
\text { keit von Kreatinin- } \\
\text { clearance und Dosis; } \\
\text { siehe Fachinfo }\end{array}$ & $H D: j$ & $\geq 12$ Jahre \\
\hline Ribavirin & 0 & ++++ & ++ & U: $10-40$ & Bili $\uparrow, \mathrm{NH}_{3} \uparrow$ & keine & keine & $\begin{array}{l}>50: 100 \% \\
50-30: 66 \%\end{array}$ & HD: $n$ & $\geq 14$ Jahre \\
\hline Oseltamivir & 3 & $(+)$ & + & A: 90 & $\begin{array}{l}\text { TA } \uparrow, \\
\text { AM-Hepatitis }\end{array}$ & - & keine & $\begin{array}{l}\text { 30-10: DI verdoppeln } \\
<10: \mathrm{KI}\end{array}$ & & $\geq 1 \mathrm{Jahr}$ \\
\hline
\end{tabular}

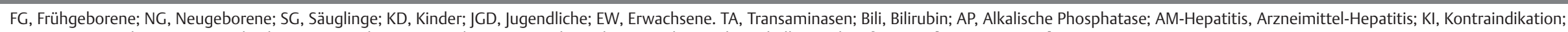
UAW, unerwünschte Arzneimittelwirkung; ONW, obere Grenze des Normwertbereiches. Angaben in den Tabellen nach Referenzen [1, 2, 16, 19, 35]. 
Foscarnet und Cidofovir. Die genannten Substanzen sollten bei Patienten mit Niereninsuffizienz vermieden bzw. nur bei Fehlen therapeutischer Alternativen unter sorgfältigem Monitoring von Nierenfunktion und Plasmaspiegeln (Aminoglykoside) eingesetzt werden.

Aufgrund der konzentrationsabhängigen bakteriziden Aktivität (je höher die Konzentration am Wirkort, desto schneller und kompletter ist die Bakterizidie), prolongierter, konzentrationsunbhängiger postantibiotischer Effekte sowie der eher zeitabhängigen Dynamik toxischer Effekte sollten Aminoglycoside auch bei Niereninsuffizienz bevorzugt einmal täglich verabreicht werden [20] (Tab. 3).

\section{Nierenersatzverfahren}

Nierenersatzverfahren sind bei progressiver Niereninsuffizienz mit Akkumulation toxischer stickstoffhaltiger Abbauprodukte (Urämie) oder unzureichender Urinausscheidung (Oligurie bzw. Anurie) indiziert. Üblicherweise besteht die Indikation zu Nierenersatzverfahren bei Erreichen einer glomerulären Filtrationsrate von 20 bis $10 \mathrm{ml} / \mathrm{min}$ bzw. der individuell festgelegten Notwendigkeit der extrakorporalen Flüssigkeitselimination. Hierzu stehen neben der Peritonealdialyse eine wachsende Zahl von Methoden (intermittierende und kontinuierliche Hämodialyse, kontinuierliche Filtrationsverfahren) zur Verfügung.

Die totale Clearance $\mathrm{CL}_{\mathrm{T}}$ einer Substanz bei Nierenersatzverfahren berechnet sich dabei aus der Summe der extrakorporalen Clearance $\mathrm{CL}_{\mathrm{EK}}$, der renalen Clearance $\mathrm{CL}_{\mathrm{R}}$ und der nicht-renalen Clearance $\mathrm{CL}_{\mathrm{NR}}$ :

$\mathrm{CL}_{\mathrm{T}}=\mathrm{CL}_{\mathrm{EC}}+\mathrm{CL}_{\mathrm{R}}+\mathrm{CL}_{\mathrm{NR}}$

Faktoren, die das Ausmaß der extrakorporalen Clearance einer Substanz bestimmen sind neben der Dauer von Dialyse bzw. Filtration u.a. das Verteilungsvolumen, die Bindung an Serumproteine, Bindung an Erythrozytenmembranen sowie Abnahme der interkompartimentellen Clearance. Eine ausgeprägte Proteinbindung sowie ein hohes Verteilungsvolumen sind dabei die wichtigsten Faktoren, die das Ausmaß der Substanzelimination durch Hämodialyse bzw. Hämofiltration begrenzen $[3,19]$.

Die intravenöse Dosierung bei Hämodialyse, Hämofiltration und Peritonealdialyse erfolgt üblicherweise wie bei terminaler Nie-

Tab. 3 Dosierung von Gentamicin bzw. Tobramycin bei Niereninsuffizienz

\begin{tabular}{ll}
\hline Initialdosis & \\
\hline Kreatininclearance $(\mathrm{ml} / \mathrm{min})$ & Dosierungsintervall (h) \\
$\geq 60$ & 24 \\
$59-40$ & 36 \\
$39-20$ & 48 \\
\hline Folgedosis & \\
$12-$ Stunden-Plasmakonzentration $(\mathrm{ug} / \mathrm{ml})$ & Dosierungsintervall (h) \\
$\leq 3$ & 24 \\
$3-5$ & 36 \\
$5-7$ & 48 \\
$>7$ & weiteres Monitoring \\
\hline
\end{tabular}

reninsuffizienz; eine Dosiserhöhung bzw. Supplementierung ist im Allgemeinen nur bei im Vergleich zur renalen und nicht-renalen Clearance substanzieller extrakorporaler Clearance, i.e., wenn die extrakorporale Clearance $>30 \%$ der renalen und extrarenalen Clearance beträgt [3].

Bei Einsatz der Peritonealdialyse können antimikrobielle Substanzen auch intraperitoneal appliziert werden, um therapeutische Plasmakonzentrationen zu erzielen und aufrechtzuerhalten. Einflussgrößen dieses Prozesses sind neben den physikochemischen Charakteristika der applizierten Substanz die Beschaffenheit der peritonealen Membran und mit der Art und Applikationsweise des Dialysates assoziierte Faktoren.

Eine ausführliche Diskussion der Dosierung von antimikrobiellen Substanzen bei Nierenersatzverfahren insbesondere bei pädiatrischen Patienten übersteigt den Anspruch dieses Beitrages. Hierfür stehen standardisierte Tabellenwerke bzw. Formeln zur Berechnung von Substanzverlusten als Referenz zur Verfügung $[1,2,35]$.

\section{Antimikrobielle Therapie bei Leberinsuffizienz}

Die Leber erhält $80 \%$ ihres Blutflusses aus dem Pfortadersystem und 20\% aus der Leberarterie. Interponiert zwischen Gastrointestinaltrakt und systemischer Zirkulation prozessiert die Leber oral verabreichte Substanzen, bevor sie die systemische Zirkulation erreichen. Unverändert oder metabolisiert können Substanzen nach systemischer Gabe in die Lebervenen gelangen oder über die Galle in den Dünndarm ausgeschieden werden, von wo sie entweder mit den Faeces eliminiert oder reabsorbiert und erneut der Leber zugeführt werden können [17, 30]. Änderungen der metabolischen und exkretorischen Funktionen durch Leberfunktionsstörungen können zur Akkumulation von Arzneistoffen, und, weniger häufig, mangelnder Bildung aktiver Metabolite führen.

\section{Hepatische Clearance}

Die hepatische Clearance ist definiert als das die Leber perfundierende Blutvolumen, das pro Zeiteinheit von einer Substanz befreit wird. Formal berechnet sich die hepatische Clearance aus Gesamtkörperclearance minus der renalen Clearance und der zumeist quantitativ nicht relevanten nichthepatischen, nichtrenalen Clearance durch andere Organe (z. B. Haut und Lunge).

Physiologische Faktoren, die die Clearance von Medikamenten durch die Leber beeinflussen, sind der Blutfluss zur Leber, die Fraktion der nicht proteingebundenen (freien) Substanz, und die intrinsische oxidative und nicht-oxidative metabolische Clearance $[32,39]$.

In dem verbreitet benutzten pharmakokinetischen Modell zur hepatischen Clearance $\mathrm{CL}_{\mathrm{H}}$ („well stirred model of hepatic clearance“) wird die Leber als singuläres Kompartiment mit dem Volumen V und dem Blutfluss Q betrachtet. Substanzkonzentrationen, die die Leber via Leberarterie und Portalvene erreichen, werden als $C_{a}$ zusammengefasst, und die im Lebervenenblut die Leber verlassenden Konzentrationen als $C_{v}$. Die intrinsische 
Clearance $\mathrm{CL}_{\text {int }}$ eliminiert die freie, nicht an Plasmaproteine gebundene Substanzfraktion $\mathrm{f}_{\mathrm{u}}$. Die intrinsische Clearance $\mathrm{CL}_{\mathrm{int}}$ ist dabei die maximale hepatische Clearance, die vorliegt, wenn der Blutfluss $Q$ und die freie Substanzfraktion $f_{u}$ ihre Rate nicht limitieren. Unter Berücksichtigung eines Equilibriums zwischen Substanzkonzentrationen in der Leber und im Lebervenenblut ergibt sich in Ableitung des Fick'schen Gesetzes die folgende Gleichung:

$\mathrm{CL}_{\mathrm{H}}=\mathrm{Q} \times\left(\left(\mathrm{f}_{\mathrm{u}} \times \mathrm{CL}_{\text {int }}\right) /\left(\mathrm{Q}+\left(\mathrm{f}_{\mathrm{u}} \times \mathrm{CL}_{\text {int }}\right)\right)\right.$

Mit diesem Modell lassen sich die Effekte von durch Lebererkrankungen bedingten Änderungen in Perfusion, Proteinbindung und intrinsischer Clearance auf die hepatische Clearance vorwiegend hepatisch eliminierter Substanzen beschreiben. Dabei können flussabhängige von kapazitätsabhängigen Substanzen unterschieden werden [39].

Bei Substanzen mit einer hohen Extraktions-Ratio (ER >0,7; $\mathrm{f}_{\mathrm{u}} \times \mathrm{CL}_{\text {int }}>\mathrm{Q}$; flussabhängige Substanzen) hängt die hepatische Clearance im Wesentlichen vom Blutfluss ab. Aufgrund der effektiven Clearance durch die Leber haben Änderungen von Plasmaeiweißbindung oder hepatozellulärer Funktion nur minimale Effekte auf die hepatische Clearance. Hämodynamische Veränderungen wie zum Beispiel bei Herzinsuffizienz oder Leberzirrhose (reduzierte Organperfusion) vermindern die hepatische Clearance von vorwiegend hepatisch eliminierten Substanzen mit hoher Extraktions-Ratio und können eine Dosisanpassung sowohl bei intravenöser als auch enteraler Applikation erforderlich machen [37].

Bei Substanzen mit niedriger Extraktions-Ratio $\left(\mathrm{ER}<0,3 ; \mathrm{f}_{\mathrm{u}} \times \mathrm{CL}_{\text {int }}\right.$ $<<$ Q; kapazitätsabhängige Substanzen) entspricht die hepatische Clearance im Wesentlichen dem Produkt von $\mathrm{f}_{\mathrm{u}} \times \mathrm{CL}_{\text {int }}$ und reagiert daher auf Änderungen der Plasmaproteinbindung und der intrinsischen Clearance; Änderungen des hepatischen Blutflusses haben hier nur minimale Effekte.

Für kapazitätsabhängige Substanzen mit hoher Plasmaeiweißbindung $\left(\mathrm{f}_{\mathrm{u}}<0,15\right)$ ist die hepatische Clearance abhängig vom Ausmaß der Proteinbindung und der intrinsischen Clearance. Hypalbuminämie kann über eine Erhöhung der freien Substanzfraktion $\mathrm{f}_{\mathrm{u}} \mathrm{zu}$ einer erhöhten hepatischen Clearance führen. Freie Substanzkonzentrationen ändern sich jedoch nicht, wenn die intrinsische Clearance unverändert bleibt. Eine Dosisanpassung ist für kapazitätsabhängige Substanzen mit hoher Plasmaeiweißbindung nur dann erforderlich, wenn die vorliegende Leberschädigung auch die intrinsische Clearance der freien Substanz ändert [37].

Für kapazitätsabhängige Substanzen mit niedriger Plasmaeiweißbindung $\left(f_{u}>0,7\right)$ ist die hepatische Clearance abhängig von der intrinsischen Clearance [37].

Nur wenige Substanzen zeigen eine intermediäre ExtraktionsRatio $(0,3<\mathrm{ER}<0,7)$. Änderungen von Blutfluss, Proteinbindung und intrinsischer Clearance können hier in variablem Ausmaß zu Änderungen der hepatischen Clearance beitragen [37].

\section{Biliäre Exkretion und enterohepatische Zirkulation}

Sehr wenige Substanzen werden von der Leber aufgenommen und unmetabolisiert in die Galle ausgeschieden. Im Gegensatz dazu werden jedoch viele polare Substanzmetabolite zumeist über aktive Transportsysteme biliär eliminiert. Substanzen, die die Galleproduktion anregen, können zu einer vermehrten, Substanzen, die den Gallefluss vermindern oder eine anderweitig bedingte Cholostase zu einer verminderten Ausscheidung biliär eliminierter Arzneistoffe und Metabolite führen. Auch führt der orale Verabreichungsweg häufig zu einer größeren biliären Exkretion als der parenterale $[31,39]$.

Substanzen oder Substanzmetabolite, die über die Gallenwege in den Dünndarm eliminiert werden, können aus dem Dünndarm unverändert oder nach Konversion in die Ausgangssubstanz wieder reabsorbiert werden. Unterbrechung der enterohepatischen Zirkulation biliär eliminierter und reabsorbierter Substanzen kann zu einer Abnahme von Plasmakonzentrationen und Halbwertszeit führen [31].

\section{Pharmakologische Konsequenzen hepatischer \\ Funktionsstörungen}

Lebererkrankungen umfassen ein weites Spektrum pathologischer Veränderungen, die eine Verminderung des transhepatischen Blutflusses, extra- oder intrahepatisches Shunting, Störungen der hepatozellulären Funktion, qualitative und quantitative Veränderungen der Serumproteine, und Änderungen des Galleflusses bewirken können. Hinzu kommen Flüssigkeitsretention und Aszites sowie im Gefolge der Lebererkrankung auftretende Nierenfunktionsstörungen (hepatorenales Syndrom), die die Disposition von Arzneistoffen weiter komplizieren können. Unterschiedliche Erkrankungen der Leber können unterschiedliche Änderungen von Absorption, Distribution und pharmakologischen Effekten zur Folge haben. Die pharmakokinetischen und pharmakodynamischen Konsequenzen einer definierten Leberstörung können interindividuell verschieden sein und auch intraindividuellen Schwankungen ausgesetzt sein. Darüber hinaus können alle wichtigen Einflussgrössen der hepatischen Clearance $\left(\mathrm{Q}, \mathrm{f}_{\mathrm{u}}, \mathrm{CL}_{\text {int }}\right)$ wie auch die Gefäßarchitektur unabhängig voneinander verändert sein [34].

Trotz Existenz einer Vielzahl möglicher Ursachen der Leberschädigung scheint die Reaktion der Leber relativ uniform und mehr vom Ausmaß als der Ursache der Schädigung bestimmt zu sein. Nach wie vor gibt es jedoch keine generell verfügbare und akzeptierte Methode, die eine Korrelation von Leberfunktionsstörung und ihren Folgen für die Disposition von Arzneistoffen erlauben würde.

Während bei akuter, viral bedingter Hepatitis die Elimination hepatisch metabolisierter Substanzen entweder normal oder nur mäßiggradig verändert ist, können akute Schädigungen der Leber durch hepatotoxische Substanzen zu hochgradigen und unmittelbaren Störungen der hepatischen Elimination führen. Die beobachteten Veränderungen sind dabei jedoch variabel und im Wesentlichen abhängig vom Ausmaß des Leberzellschadens. Bei chronischer Hepatitis oder Fettleber scheinen relevante Änderungen der hepatischen Eliminationskapazität nur in fortgeschrittenen Stadien von klinischer Relevanz zu sein. 
Die meisten Informationen zu chronischen Lebererkrankungen liegen für die Leberzirrhose vor, der gemeinsamen Endstrecke sehr unterschiedlicher chronischer Lebererkrankungen [34]. Pharmakokinetisch relevante Veränderungen bei Leberzirrhose umfassen eine absolute Abnahme von Cytochrom P450 sowie die Ausbildung intrahepatischer Shunts und extrahepatischer Umgehungskreisläufe. Die im Vordergrund stehende Perfusionsstörung betrifft vor allem die orale Bioverfügbarkeit und Clearance hepatisch eliminierter Substanzen mit hoher ExtraktionsRatio. Die Konsequenz ist eine erhöhte Exposition in der systemischen Zirkulation mit potenziell toxischer Verstärkung der pharmakologischen Effekte der entsprechenden Substanz und Notwendigkeit der Dosisreduktion [34].

Die häufig vorliegende Hypalbuminämie kann zu einer Abnahme der Bindung an Plasmaproteine führen , die durch die Akkumulation von Bilirubin und Gallensäuren im Blut weiter verstärkt werden kann. Eine reduzierte Proteinbindung kann zu einem Anstieg der hepatischen Clearance von Substanzen mit niedriger Extraktions-Ratio führen. Für Substanzen mit hoher Plasmaeiweißbindung ändern sich freie Substanzkonzentrationen jedoch nicht, wenn die intrinsische Clearance unbetroffen bleibt. Eine Dosisanpassung ist nur dann erforderlich, wenn die vorliegende Leberschädigung auch die intrinsische Clearance der freien Substanz ändert. Obwohl eine reduzierte Proteinbindung von Substanzen mit hoher Extraktions-Ratio nicht die hepatische Clearance betrifft, ist dennoch der Anteil ungebundener Substanz erhöht, kann zu einer unerwünschten Verstärkung pharmakodynamischer Effekte führen und selbst in Abwesenheit von Veränderungen anderer pharmakokinetischer Parameter eine Dosisreduktion erfordern [6, 34].

Patienten mit Leberzirrhose zeigen eine Reduktion nicht-oxidativer Metabolisierungs-reaktionen sowie eine absolute Abnahme von Cytochrom P450 in der Leber, wobei nicht alle Isoenzyme in gleichem Ausmaß und mit gleicher Kinetik betroffen sind. Eine Dosisanpassung ist für Substanzen mit niedriger Extraktionsratio und hoher Plasmaeiweißbindung dann erforderlich, wenn eine gleichzeitige Reduktion der Proteinbindung vorliegt; für Substanzen mit niedriger Extraktionsratio und niedriger Plasmaeiweißbindung ist die hepatische Clearance dagegen abhängig von der intrinsischen oxidativen und nichtoxidativen Metabolisierung und kann eine Dosisapassung erforderlich machen. Für Substanzen mit einer hohen Extraktions-Ratio hängt die hepatische Clearance im Wesentlichen vom Blutfluss ab; isolierte Änderungen der hepatozellulärer Funktion haben daher nur minimale Effekte auf die hepatische Clearance [14, 34].

\section{Antimikrobielle Therapie bei hepatischer Funktionsstörung}

Ein allgemein akzeptiertes Verfahren zur Abschätzung der Auswirkungen komplexer Leberfunktionsstörungen auf die Pharmakokinetik und Pharmakodynamik vorwiegend hepatisch eliminierter Arzneistoffe existiert nicht [7]. Bei der Erarbeitung von Dosierungsempfehlungen für Patienten mit Leberfunktionsstörungen wird am häufigsten der Pugh-Child-Score eingesetzt, der ursprünglich zur klinischen Klassifikation von alkoholischer Leberzirrhose und portaler Hypertension entwickelt wurde [24] (Tab. 4). Da in den meisten klinischen Studien zur Pharmakokinetik bei Leberinsuffizienz überwiegend Patienten mit leichten und mittelgradigen Leberfunktionsstörungen ein-
Tab. 4 Pugh-Child's Klassifikation der Leberinsuffizienz

\begin{tabular}{llll}
\hline \multicolumn{4}{c}{ Punktzuordnung (Score) } \\
Parameter & 1 Punkt & 2 Punkte & 3 Punkte \\
\hline Enzephalopathie, Grad & 0 & 1 oder 2 & 3 oder 4 \\
\hline Aszites & keiner & gering & mäßig \\
\hline Bilirubin (mg/dl) & $1-2$ & $2-3$ & $>3$ \\
\hline Albumin (g/dl) & $>3,5$ & $2,8-3,5$ & $<2,8$ \\
\hline Prothrombin-Zeit (s) & $1-4$ & $4-10$ & $>10$ \\
\hline Klassifikation der Leberfunktionsstörung & & \\
\hline Ausprägung & mild & moderat & schwer \\
\hline Score & $5-6$ & $7-9$ & $>9$ \\
\hline
\end{tabular}

Grad 0: Bewusstsein, Persönlichkeit, neurol. Untersuchung und EEG ohne path. Befund. Grad 1: Unruhe, Schlafstörung, Agitation, Irritabilität, Tremor, gestörte Handschrift, EEG-Verlangsamung. Grad 2: Lethargie, zeitliche Disorientierung, inadäquates Verhalten, Asterixis, Ataxie, langsame dreiphasige Wellen im EEG. Grad 3: Somnolenz, Stupor, örtl. Desorientierung, Hyperreflexie, Rigidität, langsame Wellen. Grad 4: Koma, nicht erweckbar, Persönlichkeit/Verhalten nicht beurteilbar, Dezerebrierung, langsame Delta-Wellen. Adaptiert von Pugh et al. (1973) [24].

geschlossen werden, existieren nur sehr beschränkte Informationen über Patienten mit schweren Leberfunktionsstörungen, obwohl hier die ausgeprägtesten pharmakokinetischen und pharmakodynamischen Veränderungen zu erwarten sind. Für die klinische Praxis ist festzuhalten, dass im Gegensatz zu Bilirubin, Serumalbumin und Prothrombinzeit die Serum-Transaminasen SGOT und SGPT nicht mit der hepatischen Clearance korrelieren [5]. Dies ist nicht überraschend, da Erhöhungen dieser Enzyme hepatozelluläre Schädigung und nicht Funktionsstörungen anzeigen.

Die Arzneimitteltherapie bei fortgeschrittener Leberinsuffizienz ist zusätzlich kompliziert durch eine Abnahme des renalen Blutflusses und der glomerulären Filtrationsrate in Abwesenheit anderer Gründe einer Niereninsuffizienz (hepatorenales Syndrom). Serum-Kreatinin und Kreatininclearance maskieren dabei häufig das Ausmaß der renalen Funktionsstörung, da die endogene Kreatininbildung bei den betroffenen Patienten oft reduziert ist: So kann das Serum-Kreatinin kann selbst bei einer Inulin-Clearance von nur $10 \mathrm{ml} / \mathrm{min}$ noch im Normbereich liegen [23]. Resultierend können Patienten mit fortgeschrittener Leberinsuffizienz und Aszites trotz normalen Serum-Kreatinins eine glomeruläre Filtrationsrate von $<60 \mathrm{ml} / \mathrm{min}$ haben, die zu einer signifikanten Akkumulation von vorwiegend renal eliminierten Substanzen wie z.B. Piperacillin und Mezlocillin führen können $[9,15]$. Als Konsequenz empfiehlt sich bei Patienten mit Leberinsuffizienz und Aszites eine Dosisanpassung selbst für Substanzen, die überwiegend renal eliminiert werden.

Untersuchungen zur Pharmakologie antimikrobieller Substanzen bei erwachsenen und insbesondere pädiatrischen Patienten mit eingeschränkter Leberfunktion sind limitiert und vorwiegend auf Patienten mit Leberzirrhose beschränkt. Der Einfluss anderer Formen von Leberfunktionsstörungen und die Beziehung zwischen dem Ausmaß des Funktionsverlustes und pharmakokinetischen Parametern sind noch weniger bekannt [37]. Relevante pharmakokinetische Parameter, Eliminationswege, intrinsische 
Hepatotoxizität und empfohlene Dosismodifikationen bei Leberinsuffizienz von häufig in der pädiatrischen Onkologie eingesetzten antimikrobiellen Substanzen sind in Tab. 2 aufgelistet. Es lassen sich folgende zusammenfassende Aussagen treffen:

- Eine Dosisanpassung bei Leberinsuffizienz von Substanzen, die nicht oder nur in geringem Ausmaß durch die Leber metabolisiert und überwiegend in unveränderter Form in den Urin ausgeschieden werden, ist der Regel nicht erforderlich, es sei denn, dass eine gleichzeitige Nierenfunktionsstörung vorliegt. $\mathrm{Zu}$ dieser Gruppe gehören

- Penicillin, Ampicillin, Ampicillin-Sulbactam, Amoxicillin, Mezlocillin, Piperacillin und Piperacillin-Tazobactam

- Cefazolin, Cefuroxim, Cefotaxim, Ceftriaxon, Ceftazidim und Cefepim

- Cefalexin, Cephaclor, Loracarbef, Cefuroximaxetil, Cefpodoximproxetil, Cefixim und Ceftibuten

- Aztreonam, Imipenem-Cilastatin und Meropenem

- alle Aminoglykoside

- die Glykopeptide Vancomycin und Teicoplanin

- Fosfomycin

- der Gyrasehemmer Levofloxacin

- die Tuberkulostatika Etambutol und Streptomycin

- die Antimykotika 5-Flucytosin und Fluconazol

- die Virustatika Aciclovir, Famciclovir, Valaciclovir, Brivudin, Ganciclovir, Valganciclovir, Cidofovir, Foscarnet und Oseltamivir

- Für die meistem Substanzen, die in relevantem Ausmaß durch die Leber metabolisiert werden, existieren keine exakten Vorgaben für eine Dosisanpassung bei Leberinsuffizienz. Generell ist Vorsicht bei mittel- und hochgradiger Leberfunktionsstörung und bei Substanzen mit oxidativer Metabolisierung geboten. Bei Fehlen therapeutischer Alternativen sollten Parameter der Leberfunktion überwacht und - nach Möglichkeit - Substanzkonzentrationen im Serum bestimmt werden, um unerwünschte Wirkungen der Muttersubstanz bzw. ihrer Metabolite durch Akkumulation zu vermeiden. Zu diesen bei Leberinsuffizienz eingeschränkt einsetzbaren Substanzen gehören

- die Kombination Amoxicillin/Clavulansäure sowie das Isoxazolylpenicillin Oxacillin

- Chloramphenicol

- Doxycyclin

- die Makrolide Erythromycin, Clarithromycin, Roxithromycin und Azithromycin

- Clindamycin

- Metronidazol

- das Streptogramin Qinupristin/Dalfopristin

- sulfonamidhaltige Kombinationen (Trimethoprim/Sulfamethoxazol; Sulfadiazin/Pyrimethamin

- die antimykotischen Triazole Itraconazol und Voriconazol

- das antimykotische Echinocandin Caspofungin

- das antimykotische Allylamin Terbinafin

- die Tuberkulostatika Rifampicin, Isoniazid und Pyrazinamid

- Substanzen, die in relevantem Ausmaß durch die Leber metabolisiert bzw. prozessiert werden und bei denen unter sorgfältigem klinischen Monitoring eine Dosisanpassung in der Regel nicht erforderlich ist, umfassen

- das Oxazolidinon Linezolid

- das Ketolid Telithromycin
- die Gyrasehemmer Ciprofloxacin und Moxiflocacin

- konventionelles und liposomales Amphotericin B

\section{Intrinsische Hepatotoxizität antimikrobieller Substanzen}

Obwohl die Leber in besonderem Masse gegenüber antimikrobiellen Substanzen exponiert ist, sind gastrointestinale oder kutane Nebenwirkungen insgesamt deutlich häufiger als Zeichen einer Leberschädigung. Von einer zytotoxischen Hepatitis (Isoniazid) über eine intrahepatische Cholostase (Makrolide, Isoxazyl-Penicilline, Clavulansäure), eine cholostatische Hepatitis (Sulfonamide, Azole, Terbinafin)) und einer kleintropfigen Steatose (Tetrazykline) werden nahezu alle Formen der Leberstörung beobachtet. In den meisten Fällen ist die Reaktion nicht dosisabhängig, sondern tritt idiosynkratisch nur bei Individuen mit besonderer Empfänglichkeit auf. Der Nachweis eines ursächlichen Zusammenhanges eines bestimmten Ereignisses mit einer Substanz ist häufig schwierig und beruht zumeist auf dem zeitlichen Zusammenhang von Gabe und Ereignis bzw. Absetzen und der Reversibilität des Ereignisses [18, 38]. Substanzen mit ausgeprägterem hepatotoxischen Potenzial sollten bei Patienten mit vorliegenden Leberfunktionsstörungen vermieden bzw. bei Fehlen therapeutischer Alternativen nur unter sorgfältiger Überwachung verordnet werden.

\section{Zusammenfassung}

Antimikrobielle Substanzen sind eine der am häufigsten eingesetzten Arzneimittel bei Kindern und Jugendlichen mit bösartigen Erkrankungen und nach hämatopoetischer Stammzelltransplantation. Funktionsstörungen von Nieren und Leber haben z.T. erhebliche Effekte auf ihre Pharmakokinetik, die zu unerwünschten Arzneimittelwirkungen oder Therapieversagen führen können. Die Kenntnis der Mechanismen der renalen und hepatischen Elimination, der pharmakologischen Konsequenzen eingeschränkter Organfunktionen sowie eine sorgfältige Abwägung von Nutzen und Risiken sind wichtige Elemente einer sicheren und effektiven antimikrobiellen Therapie. In der klinischen Praxis bleiben Funktionsstörungen von Nieren und Leber häufig unbeachtet und führen zu vermeidbarer Toxizität bzw. Therapieversagen durch Fehldosierung [22, 29]. Eine stärkere Einbindung klinischer Pharmakologen in ärztliche Verordnungsprozesse sowie computergestützte integrierte Verordnungsprogramme, die eine automatisierte patientenindividuelle Berechnung von Dosis, Dosisintervall und Aufzeigen alternativer Substanzen erlauben, könnten die Sicherheit und Effizienz der Pharmakotherapie nicht nur bei eingeschränkter Nieren- und Leberfunktion verbessern.

\section{Literatur}

${ }^{1}$ AHFS Drug Information. www.ashp.org/ahfs

${ }^{2}$ Arzneimittelinformation für Ärzte und Apotheker. www.fachinfo.de

${ }^{3}$ Atkinson AJ, Susla GM. Pharmacokinetics in patients requiring renal replacement therapy. In: Atkinson AJ, Daniels CE, Dedrick RL, Grudzinskas CV, Markey SP. Principles of clinical pharmacology. Academic Press, San Diego 2001; 51-62

${ }^{4}$ Atkinson AJ. Effects of renal disease on pharmacokinetics. In: Atkinson AJ, Daniels CE, Dedrick RL, Grudzinskas CV, Markey SP. Principles of clinical pharmacology. Academic Press, San Diego 2001; 43-49 
${ }^{5}$ Bergquist C, Lindegard J, Salmonson T. Dosing recommendations in liver disease. Clin Pharmacol Ther 1999; 66: 201 - 204

${ }^{6}$ Blaschke TF. Protein binding and kinetics of drugs in liver diseases. Clin Pharmacokinet 1977; 2: 32 - 44

${ }^{7}$ CDER, CBER. Pharmacokinetics in patients with impaired hepatic function: study design, data analysis, and impact on dosing and labeling. Guidance for Industry. Rockville, FDA 2003. http://www.fda.gov/ cder/guidance/3625fnl.doc

${ }^{8}$ Cockcroft DW, Gault MH. Prediction of creatinine clearance from serum creatinine. Nephron 1976; 16: 31 -41

${ }^{9}$ Cooper BE, Nester TJ, Armstrong DK, Dasta JF. High serum concentrations of mezlocillin in a critically ill patient with renal and hepatic dysfunction. Clin Pharm 1986; 5: 764-766

${ }^{10}$ Craig RM, Murphy P, Gibson TP, Quintanilla A, Chao GC, Cochrane C, Patterson A, Atkinson JrAJ. Kinetic analysis of D-xylose absorption in normal subjects and in patients with chronic renal failure. J Lab Clin Med 1983; 101: 496-506

${ }^{11}$ Dettli L. Individualization of drug dosage in patients with renal disease. Med Clin North Am 1974; 58: 977-985

12 Evans RS, Pestotnik SL, Classen DC, Clemmer TP, Weaver LK, Orme Jr JF, Lloyd JF, Burke JP. A computer-assisted management program for antibiotics and other antiinfective agents. N Engl J Med 1998; 338: 232 238

${ }^{13}$ Gaspari F, Perico N, Remuzzi G. Measurement of glomerular filtration rate. Kidney Int 1997; 63 (Suppl): S151 -S154

${ }^{14}$ George J, Murray M, Byth K, Farrell GC. Differential alterations of cytochrome P450 proteins in livers from patients with severe chronic liver disease. Hepatology 1995; 21: $120-128$

15 Green L, Dick JD, Goldberger SP, Angelopulos CM. Prolonged elimination of piperacillin in a patient with renal and liver failure. Drug Intell Clin Pharm 1985; 19: 427-429

${ }^{16}$ Kuemmerle HP, Murakawa T, (eds). Pharmacokinetics of antimicrobial agents. Principles - methods - application. Taylor \& Francis Inc., Abingdon, UK 1992

${ }^{17}$ Lebel MH. Pharmacology of antimicrobial agents in children with hepatic dysfunction. Pediatr Infect Dis 1986; 5: 686-690

18 Lee WM. Drug-induced hepatotoxicity. N Engl J Med 1995; 333: 1118 1127

${ }^{19}$ Livornese Jr LL, Benz RL, Ingerman MJ, Santoro J. Antibacterial agents in renal failure. Infect Dis Clin North Am 1995; 9: 591 -614

${ }^{20}$ Maderazo EG. Antibiotic dosing in renal failure. Med Clin North Am 1995; 79: 919-933

${ }^{21}$ Möller E, McIntosh JF, Slyke DD Van. Studies of urea excretion. II. Relationship between urine volume and the rate of urea excretion in normal adults. J Clin Invest 1929; 6: 427-465
${ }^{22}$ Nightingale PG, Adu D, Richards NT, Peters M. Implementation of rules based computerised bedside prescribing and administration: intervention study. BMJ 2000; 320: 750-753

${ }^{23}$ Papadakis MA, Arieff AI. Unpredictability of clinical evaluation of renal function in cirrhosis. Prospective study. Am J Med 1987; 82: 945 952

24 Pugh RN, Murray-Lyon IM, Dawson JL, Pietroni MC, Williams R. Transsection of the oesophagus for bleeding oesophageal varices. Br J Surg 1973; 60: 646-649

${ }^{25}$ Rahn KH, Heidenreich S, Bruckner D. How to assess glomerular function and damage in humans. J Hypertens 1999; 17: 309-317

${ }^{26}$ Reidenberg MM, Drayer DE. Alteration of drug-protein binding in renal disease. Clin Pharmacokinet 1984; 9 (Suppl 1): 18-26

${ }^{27}$ Reidenberg MM. Renal function and drug action. WB Saunders, Philadelphia 1971

${ }^{28}$ Reidenberg MM. The biotransformation of drugs in renal failure. Am J Med 1977; 62: $482-485$

${ }^{29}$ Rind DM, Safran C, Phillips RS, Wang Q, Calkins DR, Delbanco TL, Bleich HL, Slack WV. Effect of computer-based alerts on the treatment and outcomes of hospitalized patients. Arch Intern Med 1994; 154: $1511-1517$

${ }^{30}$ Rodighiero V. Effects of liver disease on pharmacokinetics. An update. Clin Pharmacokinet 1999; 37: 399-431

${ }^{31}$ Rollins DE, Klaassen CD. Biliary excretion of drugs in man. Clin Pharmacokinet 1979; 4: $368-379$

32 Rowland M, Benet LZ, Graham GG. Clearance concepts in pharmacokinetics. J Pharmacokinet Biopharm 1973; 1: 123-136

${ }^{33}$ Schwartz GJ, Haycock GB, Edelmann Jr CM, Spitzer A. A simple estimate of glomerular filtration rate in children derived from body length and plasma creatinine. Pediatrics 1976; 58: 259-263

${ }^{34}$ Susla GM, Atkinson AJ. Effects of liver disease on pharmacokinetics. In: Atkinson AJ, Daniels CE, Dedrick RL, Grudzinskas CV, Markey SP. Principles of clinical pharmacology. Academic Press, San Diego 2001; 63-74

35 Thomson Micromedex. www.micromedex.com/

36 Toto RD. Conventional measurement of renal function utilizing serum creatinine, creatinine clearance, inulin and para-aminohippuric acid clearance. Curr Opin Nephrol Hypertens 1995; 4: 505-509

37 Tschida SJ, Vance-Bryan K, Zaske DE. Anti-infective agents and hepatic disease. Med Clin North Am 1995; 79: 895-917

38 Westphal JF, Vetter D, Brogard JM. Hepatic side-effects of antibiotics. J Antimicrob Chemother 1994; 33: 387-401

39 Wilkinson GR, Shand DG. Commentary: a physiological approach to hepatic drug clearance. Clin Pharmacol Ther 1975; 18: 377- 390 